\title{
The effectiveness of investment subsidies: evidence from a regression discontinuity design.
}

\begin{abstract}
This paper analyzes the effects of an investment subsidy program for small and medium-sized enterprises in Flanders from 2004 to 2009. The subsidies were awarded according to a ranking system that favored young, growing and productive firms with a strong cash flow, granting subsidies to the highest scoring firms until the depletion of funds. The nature of this allocation system creates a sharp cut off in granting the subsidy according to the score, allowing us to estimate the causal impact of the subsidies using a regression discontinuity design. We find a positive effect on firm-level investment, employment, output and productivity for the firms that were granted the subsidy, but only for the small firms. However, the effect is small relative to the cost of the subsidy.
\end{abstract}

Keywords: Investment Subsidies, Policy Evaluation, Regression Discontinuity Design, Industrial Policy, Small and Medium Sized Companies

JEL Codes: C10, H71, O12 


\section{Introduction}

Despite the high amounts of state aid spent to support private business initiatives 1 the evaluations of the effectiveness of state aid are relatively rare. There is no consensus among academics on whether state aid is a suitable tool to fuel economic activity. The basic evaluation problem is that government programs might simply finance activities that firms would have undertaken in the absence of industrial policy, as noted in Criscuolo et al. (2012). Because of the difficulty to determine a plausible counter-factual of receiving state aid, it is inherently difficult to evaluate the effectiveness of state aid, see Rodrik (2012). This applies as well to our context of investment subsidies in Flanders. If the subsidies are targeted towards firms that would have invested anyway, a simple comparison between firms that received subsidies and firms that did not receive subsidies is likely to overstate the effect of the subsidies. To estimate a causal effect of the subsidies, we need to control for this selection effect.

The subsidies we investigate were issued by the Flemish government between 2004 and 2009 to firms across all sectors to stimulate investment and economic growth. To this end, the Flemish government awarded approximately $€ 250 \mathrm{M}$ of subsidies in total to small and medium-sized enterprises (SMEs). To award the subsidy, the government set up a total of 16 call systems, where firms could apply for a subsidy with an investment project. Each project was scored according to a transparent process with pre-determined and openly communicated criteria. The criteria favored firms that are young, fast growing in terms of employment and well-performing in terms of labor productivity, cash flow, use of own funds in the investment and other measures. The highest scoring applications were granted the subsidy, until the funds are depleted.

In this paper, we exploit the quasi-experimental setting of the subsidy, introduced by the sharp cut off of the call systems: firms that score below the cut off are not granted the subsidy, only firms above the cut off are granted the subsidy. This allows us to make use of the 'regression discontinuity design' (RDD) methodology (Lee and Lemieux, 2010; Cerqua and Pellegrini, 2014). Our main assumption is that firms that scored just below the cut off are a good counter-factual for firms just above the cut off. Thus, we can estimate a 'local average treatment effect' (LATE) around the cut off. The goal of our paper is to estimate the causal effect of the subsidy on our variables of interest:

\footnotetext{
${ }^{1}$ According to the State Aid Scoreboard of the European Commission, the total non-crisis state aid in the EU27 member states was $€ 67 \mathrm{~B}$ in 2012, or 0.52\% of GDP. Source: http://ec.europa.eu/ competition/state_aid/scoreboard/non_crisis_en.html
} 
investment, employment, output and productivity. The results help the policy maker in evaluating whether the subsidy program induced a higher firm growth and productivity for firms that received the subsidy. The LATE around the cut off is an interesting parameter in this context, as the cut off is the point where we would expect the highest effect. The subsidy call system favors firms that use more of their own funds in the investment and have higher cash flows. Consequently, we would expect the firms with the best score to face the lowest credit constraints and so crowding out of investments can expected to be high for these firms. Firms at the cut off have the lowest score of the firms that received the subsidy, so crowding out can be lower for these. An evaluation of the LATE tells the policy maker whether there was a causal effect of the subsidy, and consequently whether it would be useful to expand the budget for the subsidy in the future.

Our data consists of two main sources. The data of the subsidy, provided by the Flemish government, contains information on the firms, the requested subsidy, the score of the project and whether the subsidy was granted or not. We merge this data with the standard accounting data, containing yearly information on employment, capital stock and output. Our methodology and data are close to the work of Cerqua and Pellegrini (2014) who investigate the effect of subsidies in Italy.

We contribute to the literature in several ways. Our paper is one of the only papers to exploit a quasi-experimental setting in evaluating the effectiveness of general investment subsidies. In addition, we apply the setting to an economically relatively well performing region, namely Flanders, with a steady annual regional GDP growth of over 3\% from 2003 to 2009 and very limited regional differences in wealth $2^{2}$ Most other papers applying a quasi-experimental setting, such as Criscuolo et al. (2012) on the regional selective assistance program for development and intermediate areas in the UK and Cerqua and Pellegrini (2014) on Law 488 in the South of Italy, tend to focus on development areas.

Our results indicate that the causal effect of the subsidies on the growth of the receiving firms was rather limited. We find a positive effect on investment, sales, value added, employment and productivity, but statistically significant only for the small firms, e.g. firms with less than 10 employees. For larger firms we do not find any effect. The results are robust to various specifications. Possible explanations for the limited effect on larger firms include the low subsidy amount and the selection criteria to award

\footnotetext{
${ }^{2}$ Flanders has 5 provinces, which exhibit only mild differences in income per capita: the lowest income per capita was still $82 \%$ of the highest income per capita in 2009 .
} 
the subsidy. The subsidy as a percentage of the corresponding investment was rather low, possibly too low to have a measurable effect $?^{3}$ In addition, firms were selected on having a high cash flow and using own funds for investment, which favors firms that can do the investment anyway. Interestingly, the result that the impact of the subsidy only exists or is stronger for small firms is in line with Cerqua and Pellegrini (2014), Criscuolo et al. (2012) and Bronzini and Iachini (2014). This is often explained by the more difficult access of smaller firms to private funds, as explicitly modelled in Wren (1998).

The remainder of the paper is organized as follows. Section 2 provides an overview of the literature on state aid as well as some background on the subsidy. Section 3 explains the data and section 4 presents the methodology in detail. The results together with robustness checks, are presented in section 5. Section 6 presents some additional results. We conclude in section 7 .

\section{Literature review and the investment subsidy}

\subsection{Literature Review}

There is little consensus among academics regarding the effectiveness of state aid. Government programs might simply finance activities that firms would have undertaken in the absence of industrial policy (Criscuolo et al., 2012). Another often used argument against interventionism is that the government is unlikely to better assess the chances of commercial success more effectively than the market (Aghion et al., 2011). However, there are also strong arguments in favor of state aid. In general, state aid can be useful to mitigate externalities, such as knowledge spillovers or environmental damage. Another factor to consider is the existence of capital market imperfections and credit constraints, which can be alleviated by a targeted state aid policy. Aghion et al. (2015) argue that state aid is beneficial as long as it is adequately targeted and properly governed. They provide theoretical and empirical support in favor of a policy that is de-concentrated, not favoring one particular firm. They show that the degree of competition in a sector has a positive effect on the increase of total factor productivity for industrial policy targeted towards Chinese firms. Also a more spread-out subsidy over many firms within a sector has a positive effect on productivity.

\footnotetext{
${ }^{3}$ The subsidy as $\%$ of total investment was generally around $10 \%$ for most applications, see the data section for more details on the maximum $\%$.
} 
Even when the subsidy is effective in increasing investment and thus increases the scale of operation, the effect on employment could be negative. If labor and capital are complementary, an increase in capital will also induce an increase in labor. But if they are substitutes, firms will substitute capital for labor when the cost of capital is reduced through subsidies. Consequently, the subsidy could potentially decrease labor, depending on whether the scale effect or the substitution effect is the largest 4

Few papers estimate a causal effect of industrial policy targeted towards subsidizing investment and employment. The main reason is that it is inherently difficult to estimate a causal effect. Simply comparing subsidized firms with non-subsidized firms causes a positive bias in the estimated effect if the subsidies are targeted towards investments that would have happened anyway. If industrial policy is targeted towards the firms that struggle to survive and thus invest less anyway, a negative bias of the estimated effect would occur in a simple OLS regression (Rodrik, 2012).

Before firm-level data became widely available, studies focused on sectoral-level data, see e.g. Daly et al. (1993) on Canada and Schalk and Untiedt (2000) on Germany. More recent papers focus on firm-level data. However, the programs investigated are generally not discretionary, so it is difficult to estimate the appropriate counterfactual. Therefore, an alternative is to take a descriptive approach, as done by Harris and Robinson (2005) who investigated the Regional Selective Assistance (RSA) program in the UK. Other papers mitigate this issue by controlling for observables (e.g. Bergström, 2000; Koski and Pajarinen, 2013, Bia and Mattei, 2012, respectively for Swedish firms between 1987 and 1993, Finnish firms between 2003 and 2008 and Piedmont firms between 2001 and 2003), limiting the control group to firms that were eligible but did not apply (Harris and Trainor, 2005, for Northern Ireland using plant-level data from 1983-1997), or using a matching on observables approach (e.g. Bernini and Pellegrini, 2011; Bondonio and Greenbaum, 2012, respectively for Italy over the period 1996-2004 and Piedmont from 2000 to 2003). Also Czarnitzki and Lopes-Bento (2013) use matching on observables to mitigate endogeneity issues in the context of Flemish R\&D subsidies. González et al. (2005) take a distinct approach, estimating a model of firms' decisions about performing R\&D when government support can be expected and use Spanish survey data in the 1990s to explore the effects of R\&D subsidies. Some papers try to get closer to a causal effect by using an RDD approach related to ours. Bronzini and de Blasio

\footnotetext{
${ }^{4}$ For a more detailed discussion on the conditions that determine whether subsidies increase or decrease employment in a standard production function framework with perfect competition in all markets, see Criscuolo et al. (2012).
} 
(2006) investigate a similar setting as ours in Italy for the 'Law 488' program. They use the rejected firms as a control group and also include specifications where they limit the sample to firms that are in the middle of the ranking. The paper by Cerqua and Pellegrini (2014) investigates the same program for a longer time period and uses a multiple RDD approach. Bronzini and Iachini (2014) use RDD in a context of R\&D subsidies for Italy (the 'Law no. 7/2002, art. 4' program), while Jacob and Lefgren (2011) focus on the impact of National Institutes of Health (NIH) grants in the US on subsequent publications and citations. Criscuolo et al. (2012) use an instrumental variable approach instead, exploiting exogenous changes in eligibility of the different regions for the RSA program in the UK.

The results show a remarkable resemblance: the papers that take firm size heterogeneity into account, find an effect on investment that either only exists for small firms (Criscuolo et al., 2012, Bronzini and Iachini, 2014) or a positive effect across all firm sizes but higher for small firms (Cerqua and Pellegrini, 2014; Bernini and Pellegrini, 2011; Czarnitzki and Lopes-Bento, 2013; González et al., 2005). The effect on productivity is mixed: most papers do not find an effect on productivity (Cerqua and Pellegrini, 2014, Criscuolo et al., 2012; Bergström, 2000) with some exceptions who find a positive (Harris and Robinson, 2005) or negative effect (Bernini and Pellegrini, 2011).

In most countries, the subsidy granted relative to the investment was quite substantial in the context of investment programs. For the Law 488 program in Italy it was up to $50 \%$ in specific regions and $20 \%$ in other regions (Bronzini and de Blasio, 2006). The RSA progam in the UK allowed for a maximum investment subsidy of 20-30\%, depending on the region (Criscuolo et al., 2012). In Northern Ireland it was $45 \%$ Harris and Trainor, 2005). For Finland in the period 2001-2003, subsidy spending was up to $50 \%$ for some specific projects 5 and up to $10-30 \%$ for small firms and 5-20\% for medium sized firms (Tokila and Haapanen, 2012).

Other papers investigate related topics. Ham et al. (2011) find positive effects on local labor markets from government programs that encourage employment development in disadvantaged areas in the US. Devereux et al. (2007) find that the RSA discretionary government grants have a positive effect on the location decision of firms in the UK, but that firms are less responsive in areas where there are fewer existing plants in their industry. This suggests that subsidies are less effective in regions where there are limited

\footnotetext{
${ }^{5}$ For projects that 'enhance the competitiveness or internationalization of an enterprise in the longterm'.
} 
co-location benefits.

\subsection{Subsidy Background}

In 2003, the Flemish government set up an investment subsidy program aimed at small and medium-sized enterprises (SMEs) ${ }^{6}$ which was part of the general policy objective of 'increasing competitiveness of enterprises in Flanders'. The goal of the subsidy was to financially support enterprises in making their investments in Flanders. The subsidy was directed towards firms that have already 'earned their stripes in economic, ecologic and employment terms'. In addition, the subsidy should stimulate innovative firms.7 Firms across virtually all sectors could apply. From this discussion, we infer that the general goal of the subsidy was to stimulate growth for the best performing firms, which was believed to increase the overall competitiveness of the economy.

To award the subsidy in an objective manner, the government introduced a 'call' system 8 with a total of 16 calls from the year 2004 to 2009: the government calls for applications until a pre-determined deadline, and then scores each application according to a transparent process with pre-determined and openly communicated criteria. The highest scoring applications get granted the subsidy, until the funds are depleted. Small enterprises get a subsidy that is maximum $15 \%$ of the investment, while it is limited to $7.5 \%$ for medium sized firms. Later this was reduced to $10 \%$ and $5 \%$. For regions in Flanders marked as in need of economic support, the maxima were allowed to be $10 \%$ higher. The investment can only be started after the submission deadline and needs to be finished within 3 years after the subsidy decision date. The investment should be minimum $€ 12.5 \mathrm{~K}$ (€25K for firms older than 5 years) and maximum $€ 8 \mathrm{M}$. Applying is costless but requires going through the administrative process of the application $\sqrt[9]{ }$

\footnotetext{
${ }^{6} \mathrm{~A}$ small enterprise meets the following conditions: it has less than 50 employees, its yearly revenue is lower than $€ 7 \mathrm{M}$ ( $€ 10 \mathrm{M}$ from 2005 onwards) and its balance total is less than $€ 5 \mathrm{M}$ ( $€ 10 \mathrm{M}$ from 2005 onwards), and is independent (less than $25 \%$ ownership by large companies). A medium sized enterprise meets the following conditions: it has less than 250 employees, its yearly revenue is lower than $€ 40 \mathrm{M}$ ( $€ 50 \mathrm{M}$ from 2005 onwards) and its balance total is less than $€ 27 \mathrm{M}$ (€43M from 2005 onwards), and is independent (less than $25 \%$ ownership by large companies).

${ }^{7}$ These policy goals are listed e.g. in the policy note of the Flemish minister of Economy at that time Patricia Ceysens, see http://docs.vlaanderen.be/portaal/beleidsbrieven2007-2008/ceysens/ beleidsbrief_ceysens.pdf

${ }^{8}$ More background on this call system can be found in the document Ooghe and Spaenjers (2005).

${ }^{9}$ Banks offer to do the application process for the firm at a cost of $€ 350$ per application, with an extra fee of $7.5 \%$ of the subsidy if successful (minimum $€ 500$ and maximum $€ 3500$ ). Source: online document of the firm 'Pylser boekhouding \& fiscaliteit BVBA'.
} 
Each application was scored on 9 criteria relative to the other firms that applied 10 and for most of them the corresponding score is formula based. There were two broad categories in these criteria: criteria based on the goals of the subsidy, set by the policy maker ('policy criteria') and criteria to favor better performing companies ('company performance criteria'). The policy criteria were the following (+ indicates that higher is better, - indicates that lower is better): the requested subsidy as a percentage of investment vs the maximal allowed subsidy percentage (-), the degree of 'sustainable entrepreneurship' ( + , proxied by whether the firm had a sustainability certificate), the ICT level of the firm (+, proxied by whether the firm has a website or not), the age of the firm (-) and the employment evolution of the firm $(+$, from 3 years before the application to 1 year before the application). The company performance criteria were the following: auto-financing of the project $(+$, the proportion of the investment the firm will finance with its own means), the cash flow of the firm relative to total assets $(+)$, the gross value added per employee $(+)$ and the ratio of the gross wage bill and value added of the firm (-). The scores on the different categories are then re-scaled and weighted ${ }^{11}$ to become comparable and summed to yield the total score. Further details on how the score for each application is determined can be found in online appendix A.

Firms can apply multiple times. They can re-apply with the same project if their application is unsuccessful, and they can always re-apply with a new project, independent of whether they already received the subsidy. The data section discusses this more extensively, and provides an overview of the re-applications. The section also provides an overview of the different calls and corresponding summary statistics.

Note that the setup of the system is different from other investment subsidy programs. These often include requirements trying to avoid subsidizing investments that would have occurred as well without the subsidy and to mitigate the negative substitution effect on employment. For example, the Italian policy scheme studied by Cerqua and Pellegrini (2014) included the new job creation by unit of investment as a criterion. For the RSA investment subsidies, researched by Criscuolo et al. (2012), the formal criteria stipulated that the project (a) should be expected to lead to the creation of new employment or directly protect jobs of existing workers which would otherwise be lost and (b) would not have occurred in the absence of government funding. Such criteria

\footnotetext{
${ }^{10}$ Since the call of 3 June 2005 (decision date) the criterion 'requested subsidy as a \% of investment vs max allowed limit' was dropped. In addition, since the call of 15 September 2006 the criterion 'ratio gross wage bill and value added' was dropped.

${ }^{11}$ See online appendix A on the subsidy for details on the scaling.
} 
are clearly not present in the Flemish investment subsidies. On top of this, the selection criteria tend to target the most successful firms, less likely to be credit constrained. Therefore we would expect the subsidy to have a smaller impact on firm growth and employment compared to other programs. We will turn back to this issue in section 6.2.

\section{Data description}

\subsection{Data description and summary statistics for the subsidy data}

This subsection provides a description of the subsidy data, an overview of the different calls, and the summary statistics on the subsidy data.

The Entrepreneurship Agency ${ }^{12}$ a department of the Flemish government, provided us with the data on the subsidy. The data contain all firms that applied for the growth subsidy, ${ }_{13}^{13}$ and provide information on whether the firm received the subsidy, the amount of subsidy requested, the planned investment, the sub-scores on the different criteria and the total score of the firm. The data also contain a firm identifier that allows us to merge the data with the accounting data (see next subsection on the merging).

Figure 1 illustrates the distribution of the scores for the largest call in terms of number of applications ( $2^{\text {nd }}$ call). The vertical line in the graph shows the cut off: all applications with a lower score are rejected, and all applications with a higher score are accepted.

For a summary of the acceptance rate of awarding the subsidy, see Table 1 . The table shows that about $18 \%$ of the applications were granted the requested subsidy. Because firms can re-apply if the subsidy is rejected, the acceptance rate is higher in terms of number of firms: about $27 \%$. The following numbers (not shown in the table) illustrate the multiple applications per firm further. Of the 9161 firms that applied, $56 \%$ applied once, $30 \%$ applied twice and $14 \%$ applied three or more times. When an application is rejected, firms can re-apply in a future call with the same project. Of the 16148 applications, $24 \%$ are re-applications of projects that were rejected in preceding calls. Firms that are granted the subsidy, can also re-apply with new projects. Of the 2437 firms that received the subsidy, 14\% received it multiple times, of which 10\% (of

\footnotetext{
${ }^{12}$ In Dutch: Agentschap Ondernemen

${ }^{13}$ In Dutch: Groeipremie
} 


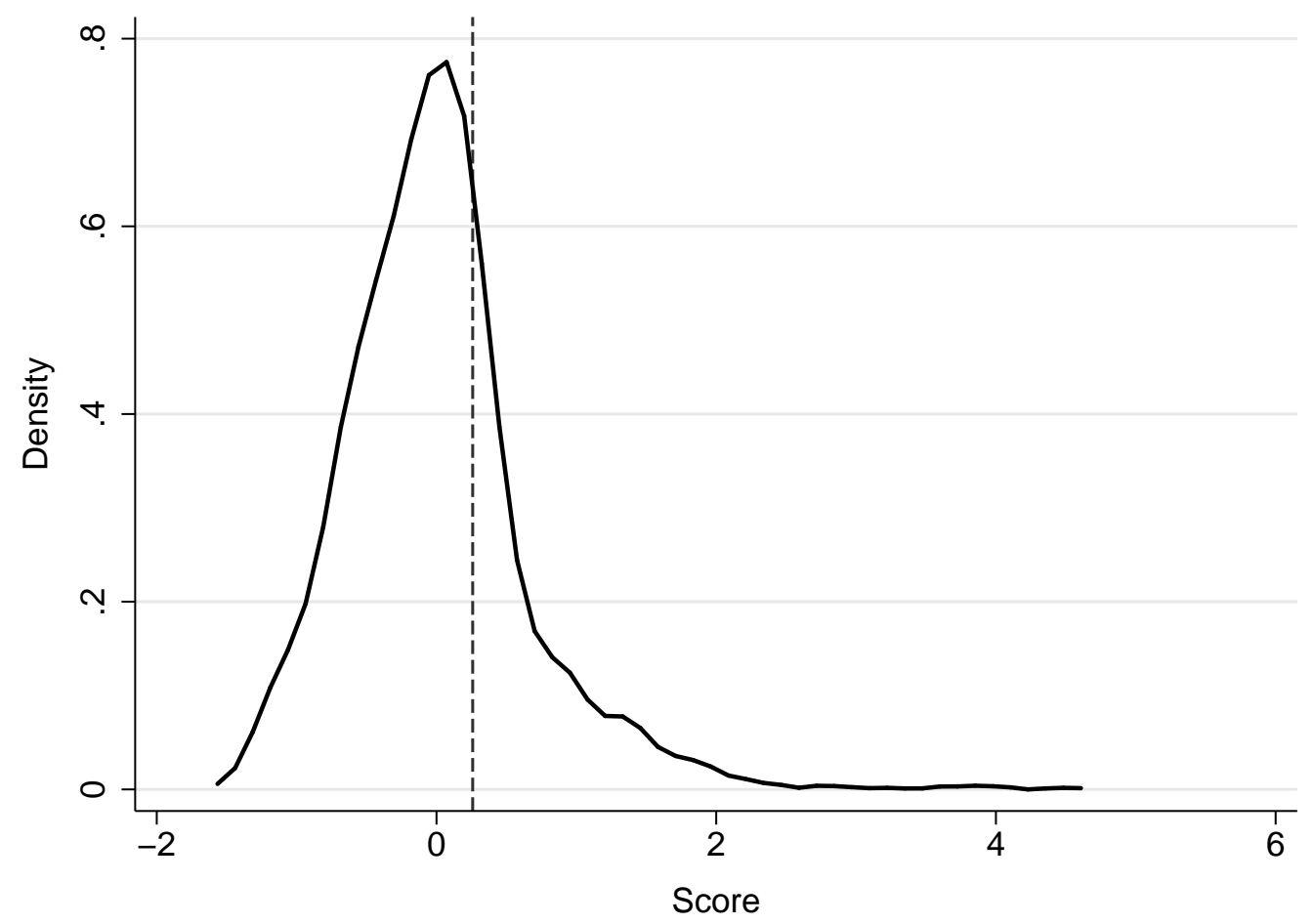

Figure 1: Density of the scores for the largest call in terms of number of applications. $\left(2^{\text {nd }}\right.$ call, decision date March 3, 2005)

Footnote: The vertical dashed line indicates the acceptance cut off.

the total number of firms that received the subsidy) two times and $4 \%$ more than two times. In theory, it was possible to apply with multiple projects in the same call, but only 6 firms did this.

To perform the econometric analysis, we need to mitigate the issue of firms that apply more than once. We do this by keeping only 1 application per firm. The application we keep is selected in the following way. For rejected firms, we keep only the best application 14 If a firm has a successful application and one or more unsuccessful applications, we keep only the first successful application of the firm 15 Also if the firm receives the subsidy multiple times, we keep only the first successful application $\sqrt{16}$ This reduces the number of applications from 16148 to 9161 (= the number of firms). These

\footnotetext{
${ }^{14}$ 'Best application' is defined as closest to the acceptance cut off. This drops 4701 applications or $29 \%$ of the original 16018 applications that remain after basic datacleaning (dropping observations with missing vat number or missing/erroneous entries for the subsidy amount or total investment amount).

${ }^{15}$ This additionally drops 1689 applications, or $11 \%$ of the original 16018 applications

${ }^{16}$ This additionally drops 479 applications, or $3 \%$ of the original 16018 applications.
} 
Table 1: Overview all calls

\begin{tabular}{rccc}
\hline \hline & Total & Accepted & Rejected \\
\hline Applications & 16148 & 2966 & 13182 \\
$(\%)$ & & 18 & 82 \\
& & & \\
Firms & 9161 & 2452 & 6709 \\
$(\%)$ & & 27 & 73 \\
\hline \hline
\end{tabular}

$\overline{\bar{a} \text { Numbers are for the full period of the subsidy. There }}$ were 16 calls for submission of application, the first was decided in July 2004 and the last in April 2009.

choices do not affect the results qualitatively ${ }^{17}$

Table 2 provides an overview of the different calls and corresponding summary statistics. We see that each call has a budget of $€ 12 \mathrm{M}$ to $€ 30 \mathrm{M}$. The total subsidy granted across the different years was almost $€ 250 \mathrm{M}$. Between 14 and $28 \%$ of the applications are rewarded a subsidy, depending on the call. The last four columns show respectively the total amount of granted subsidies, the total investment corresponding to the granted subsidies, the total amount of requested subsidies and the total investment corresponding to all the projects requesting subsidy.

See Table 3 for summary statistics on the subsidy data and the corresponding investment. The table shows that the average subsidy is about $€ 80 \mathrm{~K}$. The subsidy ranges from about $€ 7 \mathrm{~K}$ for the 10 th percentile to about $€ 200 \mathrm{~K}$ for the 90 th percentile. The corresponding investment amout is about $€ 900 \mathrm{~K}$ on average, ranging from $€ 85 \mathrm{~K}$ (10th percentile) to about $€ 2.2 \mathrm{M}$ (90th percentile). The subsidy generally covers about $10 \%$ of the investment. There are some differences between the firms that receive the subsidy and the firms that do not, but they are rather limited.

\footnotetext{
${ }^{17}$ The main results are robust to only keeping the first application of the firms that never received the subsidy instead of keeping the best application, or dropping all firms that received the subsidy and ever got rejected instead of only dropping the unsuccessful applications of these firms.
} 
Table 2: Overview per call

\begin{tabular}{|c|c|c|c|c|c|c|c|c|c|}
\hline $\begin{array}{r}\text { Index } \\
\text { call } \\
\end{array}$ & $\begin{array}{r}\text { Decision } \\
\text { date } \\
\end{array}$ & $\begin{array}{r}\text { Application } \\
\text { deadline }\end{array}$ & \# appl. & $\begin{array}{l}\text { \# acc. } \\
\text { appl. }\end{array}$ & $\begin{array}{r}\% \\
\text { acc. }\end{array}$ & $\begin{array}{r}\text { Tot. appr. } \\
\text { subs. (€M) }\end{array}$ & $\begin{array}{r}\text { Tot. inv. appr. } \\
\text { subs. }(€ M) \\
\end{array}$ & $\begin{array}{r}\text { Tot. req. } \\
\text { subs. (€M) }\end{array}$ & $\begin{array}{r}\text { Tot. req. } \\
\text { inv. (€M) }\end{array}$ \\
\hline 1 & 2-Jul-04 & 31-Mar-04 & 1410 & 391 & 28 & 30 & 275 & 122 & 1090 \\
\hline 2 & 3-Mar-05 & 31-Dec-04 & 1893 & 443 & 23 & 30 & 331 & 137 & 1430 \\
\hline 3 & 3-Jun-05 & 31-Mar-05 & 1202 & 165 & 14 & 12 & 153 & 84 & 1030 \\
\hline 4 & 15-Sep-05 & 30-Jun-05 & 976 & 201 & 21 & 12 & 136 & 66 & 788 \\
\hline 5 & 2-Dec-05 & 30-Sep-05 & 994 & 188 & 19 & 12 & 135 & 67 & 797 \\
\hline 6 & 10-Mar-06 & 23-Dec-05 & 1022 & 134 & 13 & 12 & 125 & 73 & 852 \\
\hline 7 & 6-Jun-06 & 31-Mar-06 & 1232 & 153 & 12 & 12 & 136 & 89 & 1040 \\
\hline 8 & 15-Sep-06 & 30-Jun-06 & 988 & 141 & 14 & 12 & 140 & 71 & 842 \\
\hline 9 & 14-Dec-06 & 29-Sep-06 & 761 & 126 & 17 & 12 & 131 & 58 & 673 \\
\hline 10 & 20-Apr-07 & 22-Dec-06 & 788 & 125 & 16 & 12 & 132 & 66 & 756 \\
\hline 11 & 23-Jul-07 & 30-Apr-07 & 764 & 148 & 19 & 16 & 185 & 66 & 787 \\
\hline 12 & 7-Dec-07 & 31-Aug-07 & 813 & 197 & 24 & 16 & 196 & 62 & 740 \\
\hline 13 & 21-Apr-08 & 21-Dec-07 & 878 & 178 & 20 & 16 & 204 & 72 & 880 \\
\hline 14 & 29-Jul-08 & $30-A p r-08$ & 890 & 123 & 14 & 16 & 179 & 77 & 903 \\
\hline 15 & 24-Nov-08 & 31-Jul-08 & 687 & 126 & 18 & 16 & 203 & 65 & 796 \\
\hline 16 & 15-Apr-09 & 24-Dec-08 & 850 & 127 & 15 & 16 & 168 & 76 & 909 \\
\hline Total & & & 16148 & 2966 & 18 & 249 & 2829 & 1250 & 14313 \\
\hline
\end{tabular}

$\overline{\bar{a}}$ Numbers are for the full period of the subsidy. There were 16 calls for submission of application, the first was decided in July 2004 and the last in April 2009. Firms can apply again with the same project if rejected.

${ }^{b}$ The columns refer respectively to the call index, the decision date, the application date, the number of applications, the number of accepted applications, the percentage of accepted applications, the total approved subsidy, the total investment linked to the approved subsidy, the total requested subsidy and the total investment linked to the requested subsidy. 
Table 3: Subsidy and investment summary statistics

\begin{tabular}{ll|rrr|rrrrr}
\hline \hline & & N & mean & sd & p10 & p25 & p50 & p75 & p90 \\
\hline Requested subsidy amount & No subs. & 13182 & 76 & 107 & 7 & 16 & 39 & 90 & 188 \\
(in 1,000€) & Subsidy & 2966 & 84 & 138 & 5 & 14 & 33 & 89 & 234 \\
& Total & 16148 & 77 & 113 & 7 & 16 & 38 & 90 & 193 \\
& & & & & & & & & \\
Planned total investment & No subs. & 13182 & 871 & 1,231 & 92 & 195 & 435 & 1,000 & 2,114 \\
(in 1,000€) & Subsidy & 2939 & 968 & 1,598 & 55 & 149 & 350 & 996 & 2,642 \\
& Total & 16121 & 889 & 1,306 & 85 & 180 & 417 & 1,000 & 2,200 \\
Subsidy fraction of investment & No subs. & 13182 & 0.09 & 0.03 & 0.05 & 0.09 & 0.10 & 0.10 & 0.10 \\
$(-)$ & Subsidy & 2939 & 0.11 & 0.08 & 0.05 & 0.09 & 0.10 & 0.10 & 0.15 \\
& Total & 16121 & 0.09 & 0.04 & 0.05 & 0.09 & 0.10 & 0.10 & 0.11 \\
\hline \hline
\end{tabular}

$\overline{\bar{a} \text { Numbers are for the full period of the subsidy. There were } 16 \text { calls for submission of application, }}$ the first was decided in July 2004 and the last in April 2009.

${ }^{b}$ The 'No subsidy' rows refer to firms that applied but were not granted the subsidy, the 'Subsidy' rows refer to firms that applied successfully for the subsidy, and the 'Total' rows refer to both groups, i.e. all firms that applied.

${ }^{c}$ We do not have the total investment for some of the firms that received the subsidy, therefore the number of observations is slightly smaller for 'planned total investment' and 'subsidy fraction of investment'. 


\subsection{Merge with the accounting data and pre-subsidy summary statistics}

To investigate the impact of the subsidy on various variables of interest, i.e. employment, sales, total fixed assets and labor productivity, we need to merge the subsidy data with the accounting data, obtained from the Bel-First database. This database, commercialized by Bureau Van Dijck, includes information about all Belgian firms that need to file annually an income statement and balance sheet. These are all Belgian enterprises with the exclusion of one-man businesses. The accounting data goes from 2001 (3 years before the first subsidies were awarded in 2004) to 2012 (3 years after the last subsidies were awarded in 2009). The firm identifier allows us to merge the subsidy data with the accounting data. As a substantial part of the firms that apply for the subsidy are one-man businesses, we cannot match all firms. Of the 9149 that applied for a subsidy, only 6092 have filed accounting information for at least one of the years of the period considered, and only 4931 file an accounting statement for all years going from one year before the subsidy decision to three years after the subsidy decision. We applied standard datacleaning on our sample, see online appendix B for more details. Our results therefore only apply to SMEs that are not one-man businesses.

The summary statistics on the accounting variables of our sample of firms are shown in Table 4 for the year before the subsidy on the following variables: employment, fixed assets. ${ }^{18}$ sales, value added, labor productivity (value added per worker) and age of the firm. The firms that were awarded a subsidy are larger (in terms of employment, fixed assets, sales and value added), more productive and younger. We report the same summaries for the subsample of firms that is close to the cut off in in online appendix C. More precisely, we report focus on firms for which the score is less than $1 / 3$ of a standard deviation away from the cut off value. As expected, the differences between subsidized and non-subsidized firms become smaller 19 In section 5.1, we discuss the pre-subsidy differences in more detail.

\footnotetext{
${ }^{18}$ The accounting system allows for four categories of fixed assets: start up costs, intangible fixed assets, tangible fixed assets and financial fixed assets. The subsidy can only impact intangible and tangible assets. Depreciation and amortization, used to calculate gross investment, refers to fixed assets without the financial fixed assets. Thus, we define 'fixed assets' as fixed assets minus financial fixed assets, as the latter are not included in the subsidy nor impacted by depreciation. Thus, when we use the term (total) fixed assets in the remainder of the text, we actually refer to fixed assets minus financial fixed assets.

${ }^{19}$ These differences, except for value added, turn out to be insignificant when regressing the indicator on a subsidy dummy together with call dummies.
} 
Table 4: Accounting data summary statistics in the year before the subsidy approval decision

\begin{tabular}{|c|c|c|c|c|c|c|c|c|c|}
\hline & & $\mathrm{N}$ & mean & $\mathrm{sd}$ & p10 & p25 & $\mathrm{p} 50$ & p75 & p90 \\
\hline \multirow{3}{*}{$\begin{array}{l}\text { Employment } \\
\text { (in FTEs) }\end{array}$} & No subs. & 4463 & 16 & 23 & 2 & 4 & 8 & 19 & 38 \\
\hline & Subsidy & 932 & 25 & 35 & 1 & 3 & 10 & 33 & 62 \\
\hline & Total & 5395 & 18 & 26 & 2 & 4 & 9 & 21 & 42 \\
\hline \multirow{3}{*}{$\begin{array}{l}\text { Fixed assets } \\
\text { (in } € 1000 \text { ) }\end{array}$} & No subs. & 4463 & 716 & 1135 & 65 & 160 & 378 & 814 & 1640 \\
\hline & Subsidy & 932 & 1299 & 2562 & 61 & 160 & 459 & 1393 & 3053 \\
\hline & Total & 5395 & 817 & 1499 & 64 & 160 & 388 & 871 & 1890 \\
\hline \multirow{3}{*}{$\begin{array}{l}\text { Sales } \\
\text { (in €1000) }\end{array}$} & No subs. & 4407 & 4866 & 29768 & 452 & 859 & 2030 & 4900 & 10384 \\
\hline & Subsidy & 913 & 6042 & 9173 & 415 & 847 & 2454 & 6893 & 17595 \\
\hline & Total & 5320 & 5068 & 27362 & 444 & 858 & 2065 & 5299 & 11216 \\
\hline \multirow{3}{*}{$\begin{array}{l}\text { Value added } \\
\text { (in } € 1000 \text { ) }\end{array}$} & No subs. & 4450 & 1014 & 1424 & 139 & 252 & 539 & 1197 & 2296 \\
\hline & Subsidy & 926 & 1778 & 2505 & 107 & 247 & 814 & 2219 & 4568 \\
\hline & Total & 5376 & 1145 & 1685 & 134 & 251 & 561 & 1326 & 2683 \\
\hline \multirow{3}{*}{$\begin{array}{l}\text { Value added per worker } \\
\text { (in } € 1000 / F T E \text { ) }\end{array}$} & No subs. & 4450 & 60 & 33 & 33 & 42 & 53 & 69 & 94 \\
\hline & Subsidy & 926 & 79 & 109 & 30 & 43 & 58 & 84 & 122 \\
\hline & Total & 5376 & 64 & 55 & 33 & 42 & 54 & 72 & 100 \\
\hline \multirow{3}{*}{$\begin{array}{l}\text { Age } \\
\text { (in years) }\end{array}$} & No subs. & 4411 & 18 & 13 & 5 & 9 & 15 & 23 & 34 \\
\hline & Subsidy & 904 & 12 & 11 & 2 & 3 & 9 & 17 & 28 \\
\hline & Total & 5315 & 17 & 13 & 4 & 7 & 14 & 22 & 34 \\
\hline
\end{tabular}

${ }^{a}$ Numbers are for the full period of the subsidy. There were 16 calls for submission of application, the first was decided in July 2004 and the last in April 2009.

\section{Methodology}

Our methodology is based on the regression discontinuity design (RDD) insights. Due to the set up of the subsidy score system, we have a sharp 'regression discontinuity' in our data: firms that have a score just below the cut off do not get a subsidy, while firms just above the cut off do get the full requested subsidy. Therefore we can use the RDD methodologies as set out in Lee and Lemieux (2010) and Angrist and Pischke (2008). The main assumption is that firms just below the cut off are the best control group for firms just above the cut off.

We define a dummy $D_{i}^{\text {subs }}$ which takes on the value 1 if the score of the firm $\left(s c_{i}\right)$ is above the cut off score for awarding the subsidy $\left(s c_{c o}\right)$, which means that the firm gets 
the subsidy, and 0 if the score of the firm is below the cut off score for awarding the subsidy, which means that the firm does not get the subsidy. Formally, we can write:

$$
D_{i}^{s u b s}=\left\{\begin{array}{l}
1 \text { if } s c_{i} \geq s c_{c o} \\
0 \text { if } s c_{i}<s c_{c o} .
\end{array}\right.
$$

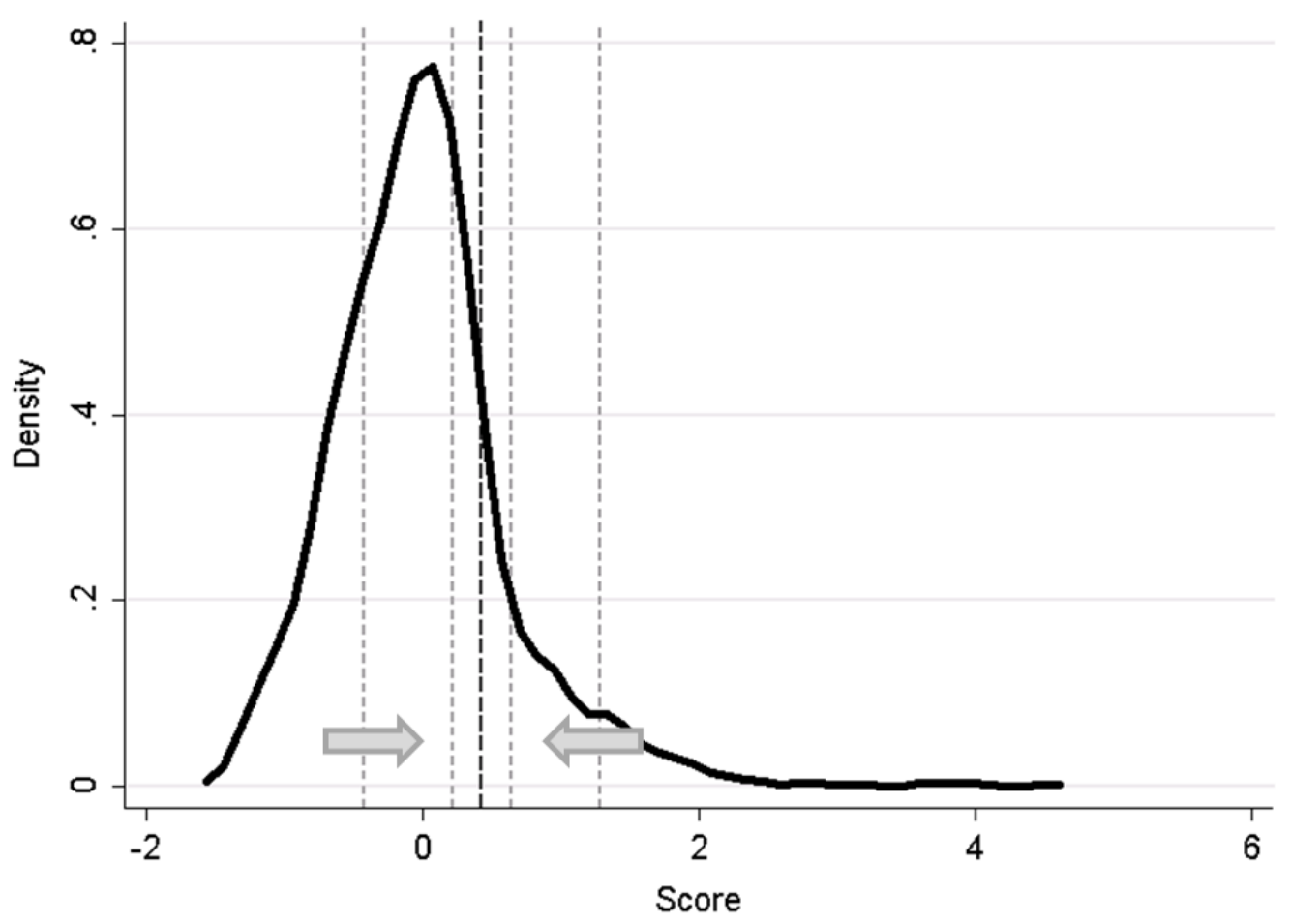

Figure 2: Density of the scores for the largest call in terms of number of applications, limiting the observations to the zone around the cut off.

Footnote: The black vertical dashed line indicates the acceptance cut off, the grey vertical dashed lines indicate the zone around the cut off that we consider to estimate the causal effect. The dashed lines furthest from the cut off correspond to a distance from the cut off of one standard deviation of the score variable, while the closest lines correspond to a distance of $1 / 4$ of the standard deviation.

To estimate the impact of the subsidy, we pool the data over the different calls and we use the cumulative four year growth from the year before the subsidy to three years after the subsidy as a dependent variable. Hereby, we use five different types of specification. First, as a benchmark, we start with a simple diff-in-diff comparison of the evolution of say employment of all firms that received the subsidy vs the firms that 
did not receive a subsidy. Formally, we use the following regression specification:

$$
\Delta_{4} Y_{i}=\frac{y_{i, 3}-y_{i,-1}}{y_{i,-1}}-1=\sigma D_{i}^{s u b s}+\lambda_{\text {call }}+\delta_{\text {sect }}+\epsilon_{i}
$$

where $\Delta_{4} Y_{i}$ represents the (cumulative) growth in the variable of interest $y_{i, t}$, e.g. employment, three years after the subsidy call decision date ('3') relative to the year before the subsidy call decision date ('-1'). $\lambda_{\text {call }}$ is the dummy for the call in which the firm participated, $\delta_{\text {sect }}$ controls for sector-specific evolutions. ${ }^{20}$ We do not need to add time dummies, as time effects are already taken up by the call dummies. This specification will simply show that firms that did get the subsidy indeed experienced a higher employment growth than firms that did not get the subsidy. The results do not have a causal interpretation yet, as firms were selected on variables that increase the likelihood of employment growth, e.g. past employment growth.

In the subsequent specifications, we do estimate a causal effect by controlling for the selection of firms that received the subsidy. In the second specification, we do this by adding a third order polynomial ${ }^{21}$ of the score to control for the selection effect $f_{c}\left(s c_{i}\right)$ on the dependent variable. Because the subsidy program consisted of multiple calls, we include a different polynomial for each call $c$ and we run the following regression:

$$
\Delta_{4} Y_{i}=\sigma D_{i}^{s u b s}+f_{c}\left(s c_{i}\right)+\delta_{\text {sect }}+\epsilon_{i t} \approx \sigma D_{i}^{s u b s}+\sum_{k=1}^{3} \beta_{c k} s c_{i}^{k}+\delta_{\text {sect }}+\epsilon_{i}
$$

As a more flexible variation of the above specification, we allow the call specific polynomial 22 to be different on both sides of the 'treatment', as advised in Lee and Lemieux (2010) and Angrist and Pischke (2008):

$$
\begin{array}{r}
\Delta_{4} Y_{i}=\sigma D_{i}^{s u b s}+\sum_{k=1}^{2}\left[D_{i}^{s u b s} \beta_{c k}^{D_{i}=1}\left(s c_{i}-s c_{c o}\right)^{k}+\left(1-D_{i}^{s u b s}\right) \beta_{c k}^{D_{i}=0}\left(s c_{i}-s c_{c o}\right)^{k}\right] \\
+\lambda_{\text {call }}+\delta_{\text {sect }}+\epsilon_{i} .
\end{array}
$$

\footnotetext{
${ }^{20}$ We define a total of 12 aggregated sectors based on the broad structure of the NACE rev2 classification. We do not pursue a narrower sector definition because of the limited number of observations in the data.

${ }^{21} \mathrm{~A}$ higher order polynomial is used to take into account possible non-linearities. Increasing the order does not have an impact on the results, but we prefer to limit the number of terms to avoid over-fitting.

${ }^{22}$ We reduced the polynomial to a second order polynomial to avoid over-fitting. Note that even then, the number of polynomial parameters to be estimated increases by one compared to the 'normal' third order polynomial, as we estimate a different second order polynomial on both sides of the treatment.
} 
This allows for a more precise estimation of the function $f_{c}\left(s c_{i}\right)$ around the cut off point.

Fourth, as a robustness check, we limit the sample to firms that are close to the cut off as illustrated before in $\left.2\right|^{23}$ This approach explicitly exploits the assumption that firms just below the cut off score are the best control group for firms just above the cut off score. More formally, we use the following:

$$
\begin{aligned}
& E\left[\Delta_{4} Y_{i}^{0} \mid s c_{i}=s c_{c o}\right] \approx\left[\Delta_{4} Y_{i} \mid s c_{i} \in\left[s c_{c o}-\Delta, s c_{c o}[]\right.\right. \\
& E\left[\Delta_{4} Y_{i}^{1} \mid s c_{i}=s c_{c o}\right] \approx\left[\Delta_{4} Y_{i} \mid s c_{i} \in\left[s c_{c o}, s c_{c o}+\Delta\right]\right]
\end{aligned}
$$

and

$$
\begin{array}{rr}
E\left[\Delta_{4} Y_{i}^{1}-\Delta_{4} Y_{i}^{0} \mid s c_{i}=s c_{c o}\right]=\lim _{\Delta \rightarrow 0} \quad E\left[\Delta_{4} Y_{i}^{1} \mid s c_{i} \in\left[s c_{c o}, s c_{c o}+\Delta\right]\right] \\
-E\left[\Delta_{4} Y_{i}^{0} \mid s c_{i} \in\left[s c_{c o}-\Delta, s c_{c o}[],\right.\right.
\end{array}
$$

where $E\left[\Delta_{4} Y_{i}^{0} \mid s c_{i}=s c_{c o}\right]$ is the expected value of the variable of interest (e.g., employment growth) at the cut off score if the firm is not awarded the subsidy (indicated by superscript ' 0 ').

For our last specification, we use a mix between the third and fourth specification: we limit the sample to firms close to the cut off, and in addition control for a linear term ${ }^{24}$ in the score variable, that is allowed to be different on both sides of the treatment.

In addition to looking for an average effect, we will also look for a heterogeneous effect across different firm sizes. To this end, we will use a linear log employment in full time equivalents (FTE's) interaction. ${ }^{25}$ The latter is done according to the following

\footnotetext{
${ }^{23}$ We limit the sample to firms that have a score that is 0.29 or less from the cut off score. The number 0.29 , which is $1 / 3$ of the standard deviation of the score, balances two objectives: the lower we take the distance to the cut off score, the more accurate all things equal, but it also implies that we have less observations and therefore lose estimation precision. We report as well results for firms at different distances from the cut off as a robustness check.

${ }^{24}$ Given the limited number of observations, we report in our base specification only the results with a linear term. Remember that the polynomial should be allowed to differ across the 16 different calls and across treatment groups. E.g. a specification with a 1st order polynomial requires an estimation of the parameter of interest, 12 sector dummies, 64 polynomial parameters $(16$ calls $\times(1$ linear term +1 call dummy) parameters for the polynomials $\times 2$ treatment groups). These are already 77 parameters with approximately 1000 observations. Given that we only keep observations close to the cut off, a linear control should suffice. We report as well specifications with a higher order polynomial. However, the Akaike information criterion indicates even that the specification without a control for the score is preferred for observations close to the cut off.

${ }^{25}$ In our analysis we use employment input converted to full time equivalents, which expresses the total labor input in terms of the number of full-time workers that would be needed to work the same amount of hours.
} 
specification:

$$
\Delta_{4} Y_{i}=\sigma D_{i}^{\text {subs }}+\beta \log F T E_{i,-1} \cdot D_{i}^{\text {subs }}+\rho \log F T E_{i,-1}+f_{c}\left(s c_{i}\right)+\lambda_{\text {call }}+\delta_{\text {sect }}+\epsilon_{i} .
$$

\section{$5 \quad$ Results}

This section gives an overview of the results. The section is organized as follows: subsection 5.1 discusses the pre-subsidy differences between the firms that received the subsidies and firms that did not. Subsection 5.2 presents graphical evidence. Subsection 5.3 shows the results for investment and subsection 5.4 shows the results for different measures of firm size (sales, value added and employment). Finally, subsection 5.5 presents the robustness checks.

\subsection{Pre-subsidy differences}

This subsection shows the differences between the firms that were granted the subsidy and the firms that were rejected, at the time before the subsidy decision is taken, and how our RDD approach eliminates these differences. To illustrate these differences, we use only the observations in the year before the subsidy is allocated, and then run an OLS regression of the dependent variable of interest on a (future) subsidy dummy, and dummies to control for the sector and the call. The results are shown in Table 5 for the variables that determine the application score.

The rows respectively show the differences for the subsidy as a percentage of the maximum allowed subsidy ('subs/max'), the sustainability certificate dummy ('sust'), a website dummy ('web'), the age of the firm in days ('age') ${ }^{26}$ the cumulative relative employment growth over two years (' $\Delta$ Emp'), the degree of autofinancing of the investment ('Autof'), the value added per worker ('Lprod'), the cash flow over total assets ('CF') and the wage bill over value added ('ULC', standing for unit labor cost). As expected, the firms that receive the subsidy request a lower subsidy compared to the maximum allowed, have a higher probability of having a sustainability certificate or a website, are younger, experienced a higher past employment growth, had a higher

\footnotetext{
${ }^{26}$ The selection score for the age criterion was age in days, with the score decreasing with age. After 5 years there was a limit, from this age onwards the score was equal to the score value of an age of five years. In the tables on the pre-subsidy differences regressions, we therefore set the age to 5 years from 5 years onwards.
} 
degree of autofinancing and performed better in terms of labor productivity, cash flow and unit labor costs 27

Next, we control for the score by including a polynomial in the score (column 2), which is allowed to be different on both sides of the cut off (column 3). We see that the differences between treated and non-treated firms disappear or at least get substantially reduced. The differences for autofinancing, webpage and sustainability remain significant. However, for sustainability and autofincancing, the coefficients switch sign, so if these would be driving the results, we would see the estimated impact of the subsidy to change from specification to specification. Moreover, when we focus on firms that are close to the threshold in columns (4) and (5) the differences disappear ${ }^{28}$ We have executed the same procedure for the sample of small firms (10 employees or less), and obtained similar results.

In online appendix D we report the differences between subsidized and non-subsidized firms in terms of employment, value added, sales and fixed assets. Again, the initial differences between the two groups disappear once controlling for the score and narrowing the sample to firms close to the cut off.

We perform as well a test to check whether the firms can manipulate the assignment of the subsidies. In this case, we would observe a discontinuity in the assignment variable at the value of the cut off. We used the test proposed by McCrary (2008) and find no significant discontinuity in the distribution of the scores around the cut off (see Figure D.1 in online appendix D). ${ }^{29}$

\footnotetext{
${ }^{27}$ The number of observations varies across the different indicators due to data availability and because some indicators were only used for a limited number of calls.

${ }^{28}$ There are no results for the sustainability indicator as there are not enough firms with a sustainability certificate close to the threshold. (less than $1 \%$ of the firms has a certificate)

${ }^{29}$ Note moreover that at the moment of application, the cut off score was not known to the firms as it depends on the scores of all firms as well as their requested subsidy amount. The large number of applicants at each call makes collusion as well highly implausible.
} 
Table 5: Pre-subsidy differences between firms that received the subsidy and firms that did not

\begin{tabular}{|c|c|c|c|c|c|c|c|}
\hline & \multicolumn{3}{|c|}{ All Firms } & \multicolumn{4}{|c|}{ 1/3 St. Dev. } \\
\hline & $\begin{array}{c}\text { No Control } \\
\text { (1) }\end{array}$ & $\begin{array}{c}\text { Poly Control } \\
\text { (2) }\end{array}$ & $\begin{array}{l}2 \text { Sided Contr. } \\
\text { (3) }\end{array}$ & Obs & $\begin{array}{c}\text { No Control } \\
(6)\end{array}$ & $\begin{array}{c}2 \text { Sided Contr. } \\
(5)\end{array}$ & Obs. \\
\hline \multirow[t]{2}{*}{ subs/max } & $-0.126^{* *}$ & 0.0518 & 0.0220 & 1494 & -0.00448 & 0.0144 & 534 \\
\hline & $(0.018)$ & $(0.0314)$ & $(0.0358)$ & & $(0.0253)$ & $(0.0430)$ & \\
\hline \multirow[t]{2}{*}{ sust } & $0.0565^{* *}$ & $-0.0285^{* *}$ & $0.0229^{* *}$ & 5395 & & . & 1203 \\
\hline & $(0.0078)$ & $(0.00460)$ & $(0.00416)$ & & () & () & \\
\hline \multirow[t]{2}{*}{ web } & $0.153^{* *}$ & $0.0371^{+}$ & $0.0760^{* *}$ & 5395 & 0.000663 & -0.0250 & 1203 \\
\hline & $(0.0127)$ & $(0.0207)$ & $(0.0249)$ & & $(0.0171)$ & $(0.0277)$ & \\
\hline \multirow[t]{2}{*}{ age } & -0.241 & -0.00356 & 0.00796 & 5395 & $-0.0449^{*}$ & -0.0314 & 1203 \\
\hline & $(0.0164)$ & $(0.0201)$ & $(0.0242)$ & & $(0.0180)$ & $(0.0270)$ & \\
\hline \multirow[t]{2}{*}{$\Delta \mathrm{Emp}$} & $0.172^{* *}$ & -0.00194 & -0.0335 & 4531 & 0.0346 & -0.0609 & 952 \\
\hline & $(0.0192)$ & $(0.0315)$ & $(0.0371)$ & & $(0.0216)$ & $(0.0442)$ & \\
\hline \multirow[t]{2}{*}{ Autof } & $0.165^{* *}$ & $-0.0898^{* *}$ & $-0.0581^{+}$ & 5395 & $0.0366^{+}$ & 0.0209 & 1203 \\
\hline & $(0.0134)$ & $(0.0267)$ & $(0.0328)$ & & $(0.0216)$ & $(0.0399)$ & \\
\hline \multirow[t]{2}{*}{ Lprod } & $0.0904^{* *}$ & -0.0355 & -0.0370 & 5375 & 0.0342 & -0.00812 & 1198 \\
\hline & $(0.0162)$ & $(0.0314)$ & $(0.0393)$ & & $(0.0255)$ & $(0.0485)$ & \\
\hline \multirow[t]{2}{*}{$\mathrm{CF}$} & $0.0364^{* *}$ & $0.0111^{+}$ & 0.00257 & 5391 & $0.0231^{* *}$ & 0.0101 & 1203 \\
\hline & $(0.00334)$ & $(0.00615)$ & $(0.00760)$ & & $(0.00508)$ & $(0.00946)$ & \\
\hline \multirow[t]{2}{*}{ ULC } & $-0.0633^{* *}$ & -0.0233 & -0.0106 & 3174 & $-0.0418^{* *}$ & $-0.0424^{+}$ & 904 \\
\hline & $(0.00876)$ & $(0.0167)$ & $(0.0198)$ & & $(0.0134)$ & $(0.0244)$ & \\
\hline
\end{tabular}

$a \overline{\text { Robust standard errors in parentheses. }{ }^{+} p<0.10,{ }^{*} p<0.05,{ }^{* *} p<0.01}$

${ }^{b}$ All models include call and sector dummies. Model 1 is for the full sample without controlling for score. Model 2 includes a $3^{\text {rd }}$ order polynomial in the score. Model 3 includes a $2^{\text {nd }}$ order polynomial allowed to be different on both sides of the cut off. In models 4 and 5 , the sample is limited to firms close to the cut off, i.e. $1 / 3$ standard deviation of the score variable. Model 4 does not control for the score. Model 5 includes a linear control in the score that is allowed to be different on both sides of the cut off.

${ }^{c}$ Dependent variable indicated in the row: the maximum allowed subsidy ('subs/max'), the sustainability certificate dummy ('sust'), a website dummy ('web'), the log age of the firm in days ('age'), the cumulative relative employment growth over two years (' $\Delta$ Emp'), the degree of autofinancing of the investment ('Autof'), the log value added per worker ('Lprod'), the cash flow over total assets ('CF') and the wage bill over value added ('ULC', standing for unit labor cost).

${ }^{d}$ subs/max and ULC are only used as a criterion for the score for a limited number of calls. We only include observations for the calls where they are used. 


\subsection{Graphical Evidence}

We first present some graphical evidence on the effect of the subsidy on the main variables of interest. To this end, we divide the standardized score variable in a number of bins and compute the average value of each indicator within these bins. These average values are plotted against the midpoint of the bin. Figure 3 presents the results of this exercise for fixed assets growth, sales growth, value added growth and employment growth ${ }^{30}$ We also show the fit of a polynomial regression model, estimated separately on each side of the cut off point, together with the $95 \%$ confidence intervals. At best, these figures show a small impact of the subsidy on fixed assets, sales, value added and employment growth.

When turning to a subsample of small firms however, here defined as firms with 10 or less employees in the year before the subsidy, the picture changes. Figure 4 shows some first evidence of a positive effect of the subsidy on input and output growth. We will formally test these differences between subsidized and non-subsidized firms in our econometric framework in the following subsections.

\footnotetext{
${ }^{30}$ Results are displayed for observations within one standard deviation of the cut off. The bin size is equal to 0.05. Similar results are obtained with different values for the bin size. To test for the width of the bin, we follow Lee and Lemieux (2010) and use the idea that if the bins are narrow enough, there should be no systematic relationship between the indicator and the score within each bin. We test for this by adding a set of interactions between the bin dummies and the score to a regression of the indicator on the bin dummies and testing whether the interactions are jointly significant. We do not find this to be the case.
} 

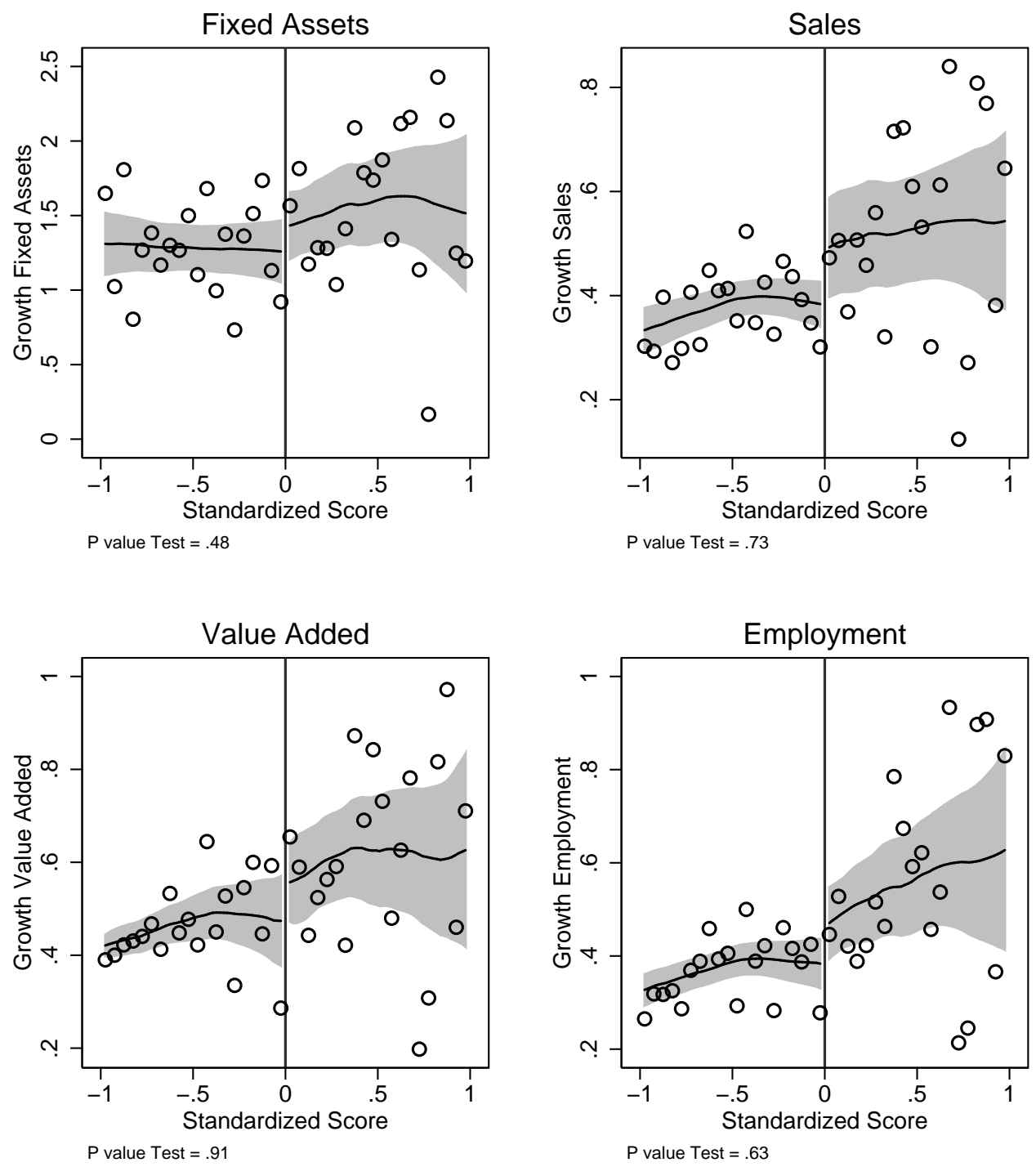

Figure 3: Effect of subsidy on main indicators

Footnote: Bin size is 0.05. Graph restricted to firms within one standard deviation from the cut off. A local polynomial smooth is added to the graph together with its confidence interval. The p-value a test for the interactions between the bin dummies and the score being jointly equal to zero in a regression of the indicator on the bin dummies and these interactions, is reported below each pane. 

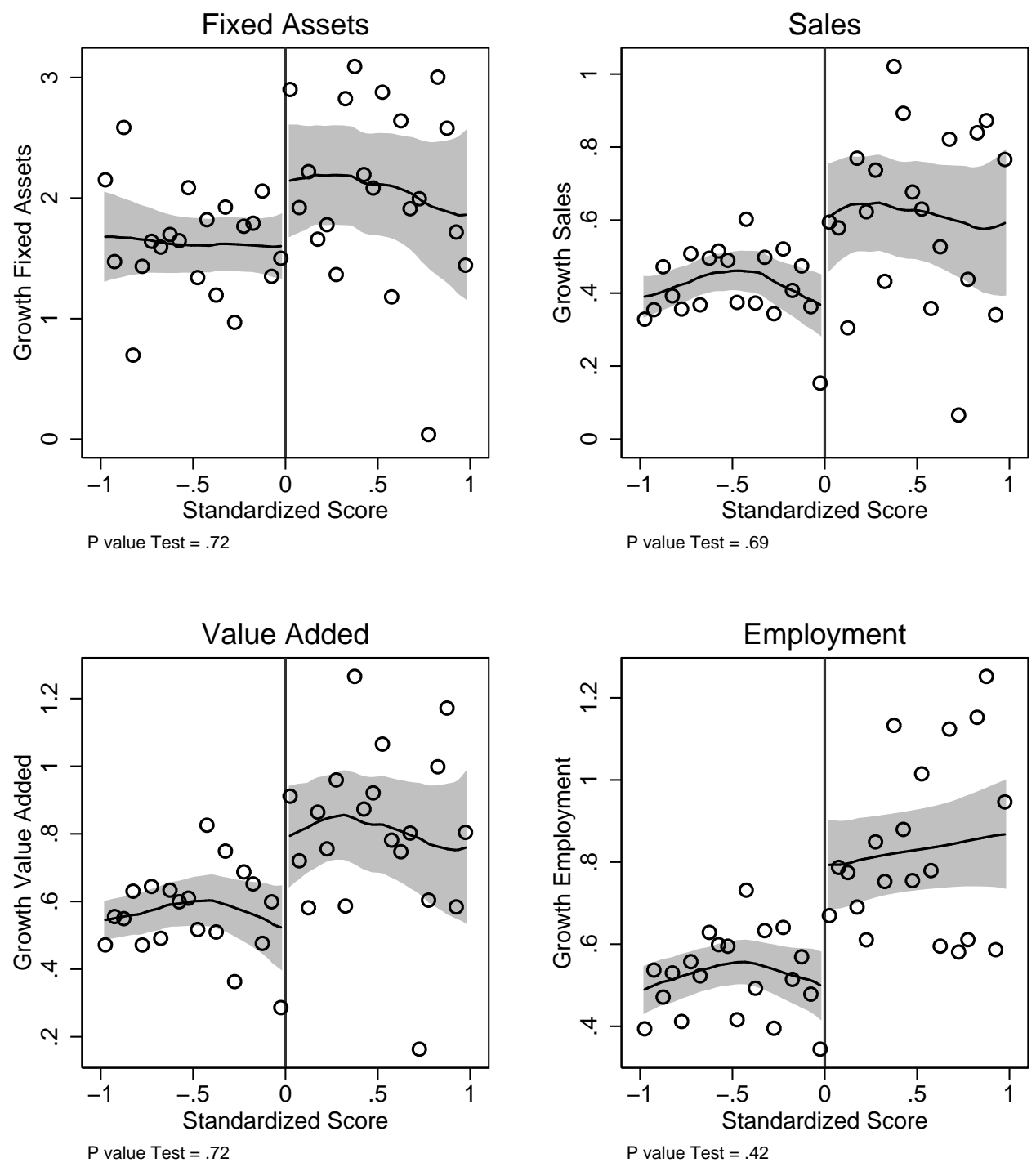

Figure 4: Effect of subsidy on main indicators, small firms

Footnote: Bin size is 0.05. Graph restricted to firms within one standard deviation from the cut off. A local polynomial smooth is added to the graph together with its confidence interval. The p-value of test for the interactions between the bin dummies and the score being jointly equal to zero in a regression of the indicator on the bin dummies and these interactions is reported below each pane. 


\subsection{Results for Investment}

This subsection shows the results for various measures of investment. We first show results for net investment, i.e. changes in fixed assets. Later, we also show results for gross investment, taking into account depreciation and amortization. In Table 6] we present the 5 different specifications as explained in the methodology section in the columns. In the first column, as a benchmark, we show the difference in fixed asset growth between firms that received the subsidy and firms that did not, as specified in equation (2). Firms that received the subsidy had a cumulative growth that was approximately 33 percentage points higher. In the next 4 columns however, we see that there is little evidence for a causal effect. In the second column, we control for a polynomial in the score that the firms were given in the call, which corresponds to specification (3) in the methodology section. The effect becomes substantially smaller and is no longer statistically significant from zero. The coefficient is smaller in the rest of the columns and is never statistically significant. In the third column, we control for a polynomial that can differ across treatment group, see specification (4). The fourth column is a diff-in-diff comparison between firms that received the subsidy and firms that did not receive the subsidy, but with the sample limited to firms that are close to the subsidy approval cut off. The fifth column shows the results for the reduced sample, but with a linear control for the score.

Table 6: Effect of the subsidy on cumulative four year fixed assets growth after receiving the subsidy

\begin{tabular}{lccccc}
\hline \hline & $\begin{array}{c}(1) \\
\text { All firms }\end{array}$ & $\begin{array}{c}(2) \\
\text { All firms }\end{array}$ & $\begin{array}{c}(3) \\
\text { All firms }\end{array}$ & $\begin{array}{c}(4) \\
\text { Close firms }\end{array}$ & $\begin{array}{c}(5) \\
\text { Close firms }\end{array}$ \\
\hline$D^{\text {subs }}$ & $0.330^{* *}$ & 0.232 & 0.188 & 0.0954 & 0.0368 \\
& $(0.0996)$ & $(0.189)$ & $(0.229)$ & $(0.150)$ & $(0.275)$ \\
\hline Polynomial Control & No & $3^{\text {rd } \text { Ord. }}$ & $2^{\text {nd }}$ Ord. & No & $1^{\text {st } \text { Ord. }}$ \\
& & & 2 sides & & 2 sides \\
\hline Observations & 4857 & 4857 & 4857 & 1112 & 1112 \\
$R^{2}$ & 0.031 & 0.044 & 0.049 & 0.071 & 0.122 \\
\hline \hline
\end{tabular}

$\overline{{ }^{b} \text { Robust standard errors in parentheses. }{ }^{+} p<0.10,{ }^{*} p<0.05,{ }^{* *} p<0.01}$

${ }^{a}$ Dependent variable: cumulative growth in fixed assets 3 years after the subsidy allocation relative to the year before the subsidy (year '-1')

${ }^{b}$ The columns refer to the 5 different specifications explained in the methodology section. In columns 4 and 5 , the sample is limited to firms close to the cut off, i.e. within $1 / 3$ standard deviation of the score variable. All specifications include call and sector dummies 
Interestingly, we get a different picture when we allow for heterogeneous effects according to the size of the firm. We interact the treatment with the size of the firm, as explained in equation (5). The results are reported in Table 7. Focusing on the full sample, fixed assets growth is higher for firms that received the subsidy, but the effect is decreasing in the size of the firm, measured by the log of employees before the subsidy. More precisely, from column (2), fixed assets growth increases by $54.5 \%$ points for firms with one FTE in the year before the subsidy. This percentage drops by approximately $13.1 \%$ points for each increase in $\log$ FTE by 1, e.g. for the median employment before the subsidy of 9 , the total effect is reduced to approximately $25 \%$. This heterogeneity is size is in line with earlier results of Bronzini and Iachini (2014), Cerqua and Pellegrini (2014) and Criscuolo et al. (2012) ${ }^{31}$

The estimated coefficients are of similar size across the last three columns, but they lose their statistical significance when focusing only on the firms close to the cut off, probably due to a loss in precision due to the lower sample size.

To facilitate the interpretation of the magnitude and the statistical significance of the results, we present the results of column (2) graphically in figure 5. The graph shows that the effect is positive but statistically significant only for the smallest firms: for firms with more than 5 employees, the estimated effect is no longer statistically significant at the $10 \%$ level. The estimated effect itself goes down to zero for firms with 64 employees. Note however that the $90^{\text {th }}$ percentile of initial employment is equal to 62 , so the number of firms for which the impact of the subsidy is predicted to be negative is limited and for no firm the predicted impact is significantly negative 2

Obviously, the choice of the bandwidth for the restricted sample, namely $1 / 3$ of a standard deviation is arbitrary so we checked the results for different values of this bandwidth. More precisely, we ran the same regression where we keep only firms within respectively $1,1 / 2,1 / 3,1 / 4$ and $1 / 5$ standard deviation of the score variable. For each of the different bandwidths we include no polynomial, a first order and a second order polynomial in the score. We also report the Akaike information criterion to test which order of the polynomial is the most appropriate. The results are reported in Table E.1 in online appendix E. The picture that emerges from these different specifications appears to be robust against the choice of different bandwidths or polynomials. Note moreover

\footnotetext{
${ }^{31}$ We found similar results when doing a split sample and focusing only on small firms, instead of working with an interaction term.

${ }^{32}$ Given the winsorization, the firms for which the point estimate is negative are in fact as well out-of-sample.
} 
Table 7: Effect of the subsidy on cumulative four year fixed assets growth after receiving the subsidy - interaction with initial log employment

\begin{tabular}{lccccc}
\hline \hline & $(1)$ & $(2)$ & $(3)$ & $(4)$ & $(5)$ \\
& All firms & All firms & All firms & Close firms & Close firms \\
\hline$D^{\text {subs }}$ & $0.710^{* *}$ & $0.545^{+}$ & $0.599^{+}$ & 0.572 & 0.533 \\
& $(0.226)$ & $(0.284)$ & $(0.322)$ & $(0.388)$ & $(0.459)$ \\
$\log (\mathrm{FTE})$ before $\times D^{\text {subs }}$ & $-0.151^{*}$ & $-0.131^{+}$ & -0.115 & -0.188 & -0.196 \\
& $(0.0741)$ & $(0.0752)$ & $(0.0764)$ & $(0.126)$ & $(0.126)$ \\
$\log (\mathrm{FTE})$ before & $-0.342^{* *}$ & $-0.344^{* *}$ & $-0.344^{* *}$ & $-0.315^{* *}$ & $-0.301^{* *}$ \\
& $(0.0350)$ & $(0.0357)$ & $(0.0357)$ & $(0.0783)$ & $(0.0780)$ \\
\hline Polynomial Control & No & $3^{\text {rd }}$ Ord. & $2^{\text {nd }}$ Ord. & No & $1^{\text {st }}$ Ord. \\
& & & 2 sides & & 2 sides \\
\hline Observations & 4857 & 4857 & 4857 & 1112 & 1112 \\
$R^{2}$ & 0.061 & 0.072 & 0.076 & 0.111 & 0.158 \\
\hline \hline
\end{tabular}

$\overline{{ }^{a} \text { Robust standard errors in parentheses. }{ }^{+} p<0.10,{ }^{*} p<0.05,{ }^{* *} p<0.01}$

${ }^{a}$ Dependent variable: cumulative growth in fixed assets 3 years after the subsidy allocation relative to the year before the subsidy (year '-1')

${ }^{b}$ The columns refer to the 5 different specifications explained in the methodology section. In columns 4 and 5 , the sample is limited to firms close to the cut off, i.e. within $1 / 3$ standard deviation of the score variable. All specifications include call and sector dummies

that the Akaike information criterion indicates that a zero order polynomial is preferred. 


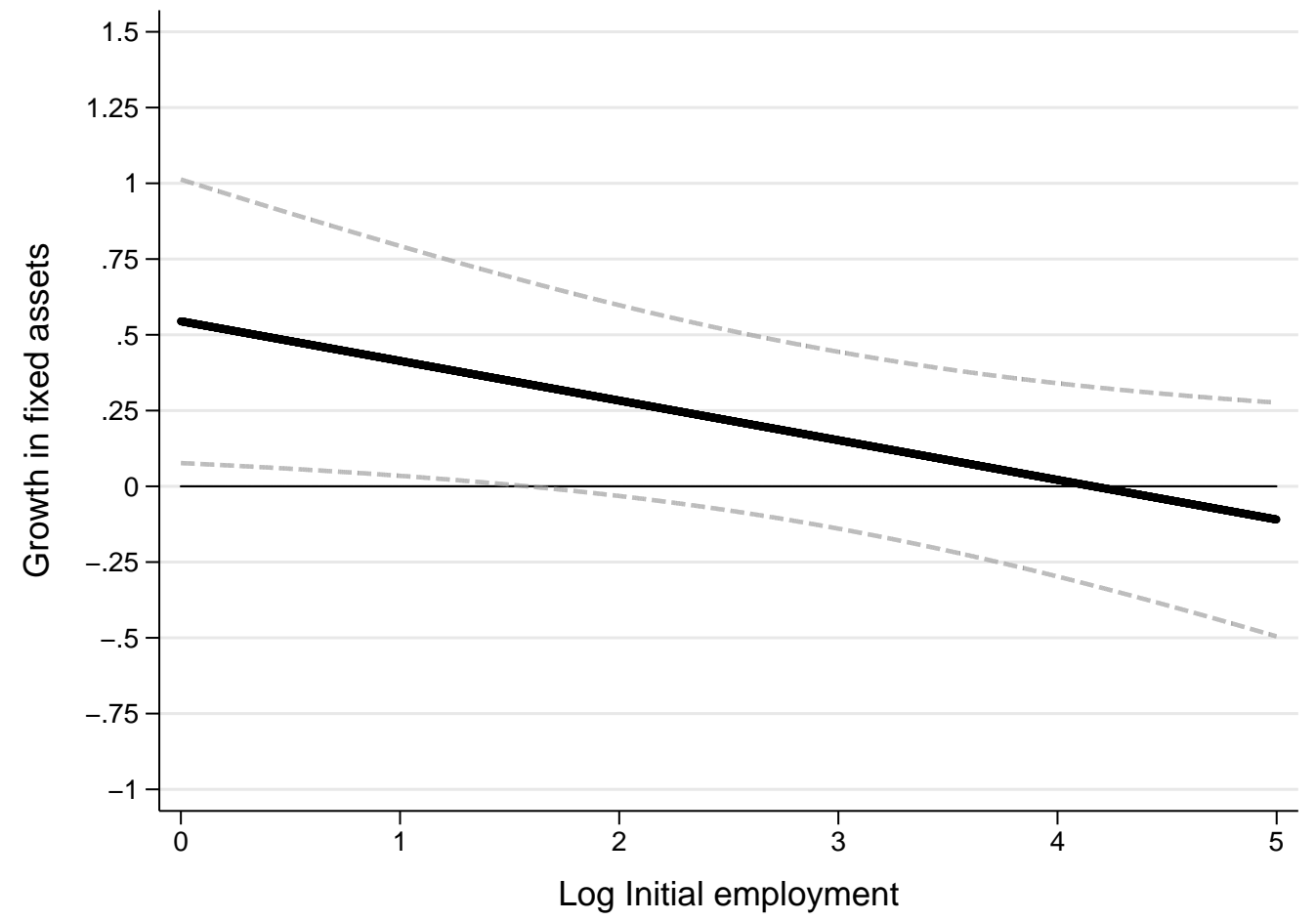

Figure 5: Illustration of the heterogeneous effect on fixed asset growth with regards to initial firm size.

Footnote: Firm size is captured by initial employment in logs. The black line represents the estimated effect according to column 3 in Table 7, the gray dashed lines indicate the $90 \%$ confidence interval. The variance of the effect is calculated according to the following formula: $\operatorname{var}\left(\frac{\partial \Delta_{4} Y_{i}}{\partial D_{i}^{s u b s}}\right)=\operatorname{var}(\sigma)+$ $\log F T E_{i,-1}^{2} \operatorname{var}(\beta)+2 \log F T E_{i,-1} \operatorname{cov}(\sigma, \beta)$. The point estimate for the effect of the subsidy becomes negative at $4.16 \log$ initial employment, which corresponds to 64 employees.

We also analyzed gross investment, taking into account depreciation and amortization. In Table 8 we report the results for cumulative gross investment from the year before the subsidy to 3 years after the subsidy was awarded, relative to the initial fixed assets. As for net investment, we do not find a general effect for gross investment across all firm sizes (results not shown here). Table 8 shows the results for the size interaction specification. All coefficients again have the same sign and order of magnitude (taking into account the standard errors) across specifications and are statistically significant except for the first one in column (5). Again, the different specifications with different bandwidths are reported in Table E.1 in online appendix E and basically show a similar, consistent picture.

Although the coefficients are not always statistically significant - especially for 
Table 8: Effect of the subsidy on cumulative four year gross investment after receiving the subsidy - interaction with initial log employment

\begin{tabular}{lccccc}
\hline \hline & $(1)$ & $(2)$ & $(3)$ & $(4)$ & $(5)$ \\
& All firms & All firms & All firms & Close firms & Close firms \\
\hline$D^{\text {subs }}$ & $1.287^{* *}$ & $0.972^{*}$ & $1.252^{* *}$ & $1.089^{+}$ & 1.016 \\
& $(0.345)$ & $(0.429)$ & $(0.484)$ & $(0.588)$ & $(0.689)$ \\
& & & & & \\
$\log (\mathrm{FTE})$ before $\times D^{\text {subs }}$ & $-0.269^{*}$ & $-0.248^{*}$ & $-0.250^{*}$ & $-0.339^{+}$ & $-0.351^{+}$ \\
& $(0.114)$ & $(0.115)$ & $(0.116)$ & $(0.193)$ & $(0.191)$ \\
$\log (\mathrm{FTE})$ before & $-0.463^{* *}$ & $-0.467^{* *}$ & $-0.466^{* *}$ & $-0.468^{* *}$ & $-0.472^{* *}$ \\
& $(0.0526)$ & $(0.0537)$ & $(0.0537)$ & $(0.116)$ & $(0.116)$ \\
\hline Polynomial Control & No & $3^{\text {rd }}$ Ord. & $2^{\text {nd }}$ Ord. & No & $1^{\text {st }}$ Ord. \\
& & & 2 sides & & 2 sides \\
\hline Observations & 4661 & 4661 & 4661 & 1072 & 1072 \\
$R^{2}$ & 0.058 & 0.071 & 0.076 & 0.129 & 0.175 \\
\hline \hline
\end{tabular}

$\overline{\bar{a}}$ Robust standard errors in parentheses. ${ }^{+} p<0.10,{ }^{*} p<0.05,{ }^{* *} p<0.01$

${ }^{b}$ Dependent variable: $\log$ cumulative gross investment, aggregated over 4 years, starting from the year the subsidy is awarded to 3 years after the decision year of the subsidy.

${ }^{c}$ The columns refer to the 5 different specifications explained in the methodology section. In columns 4 and 5 , the sample is limited to firms close to the cut off, i.e. within $1 / 3$ standard deviation of the score variable. All specifications include call and sector dummies.

net investment - the same picture shows across specifications: the subsidies had a positive effect on investment for the smallest firms, but this effect rapidly declines with increasing firm size. Shown separately, the lack of statistical significance in some of the specifications might cast some doubt on the evidence, but the next subsection shows that the evidence for other measures of firm growth, i.e. increase in sales, value added and employment, is more robust. This suggests that the fact that some specifications do not show statistically significant coefficients for investment, might be due to measurement noise. Fixed assets is typically a rather complex and noisy variable, where the reporting is influenced by the tax implications, i.e. the goal of the firm is not to report its fixed assets as accurately as possible, but rather to minimize taxes paid. 


\subsection{Results for Firm Growth}

In addition to the effect on investment, we have also analyzed the effect on the other variables of interest. More precisely, we estimate the impact of the subsidy on two output related variables, namely value added and sales as well as on employment.

Table 9 displays the results. Again, we show results for the 5 different specifications, allowing the effect do differ between different firm sizes. The first column shows that firms receiving the subsidy witnessed higher sales and value added growth, and the effect is larger for small firms. The causal impact of the subsidy is lower however, as controlling for the score substantially reduces the estimated coefficient. For example, the estimated sales growth for a firm with one employee is equal to $18.1 \%$ when controlling for the score in column (2), down from $29.3 \%$ in column (1). The size heterogeneity in the estimated impact for sales of column (2) is illustrated in figure 6. According to this specification, the effect is no longer statistically significant for firms with 11 employees and becomes zero for firms with approximately 45 employees. Again, the level of employment for which the effect becomes significantly negative is out-of-sample. The results for columns (3) to (5) are qualitatively similar. This effect remains highly statistically significant in all specifications, even when looking at small subsample of firms close to the cut off. Similar findings are found for value addded, namely a positive effect of the subsidy, but only for the small firms. We again ran robustness checks varying the bandwidth and the included polynomial. Results are reported in Table E.2 in online appendix E . The finding of positive impact of the subsidy on sales and value added growth appears to be robust for different values of the bandwidth as well as polynomial. Again, according to the Akaike information criterion, the zero order polynomial specification is the preferred one, except for the sample one standard deviation from the cut off.

The effect of the subsidy on employment growth is reported in the bottom pane of Table 9. Again, the specifications indicate that there is a positive effect of the subsidy on employment growth, but only for the small firms 33 We will see in Section 6.2 that the impact on employment is low relative to the cost of the subsidy, even for the specifications where we find a significant positive effect on employment. Varying the bandwidth and order of the polynomial gives similar results (bottom rows in Table E.2 in online appendix $\mathrm{E}$ ) and the Akaike information criterion indicates that the

\footnotetext{
${ }^{33}$ In the last specification, the estimated effect becomes insignificant, but given the robustness if the estimate over the other specifications, we continue with the assessment that there is a positive effect on employment.
} 
specification without including a polynomial in the score is the preferred one ${ }^{34}$, 35

All in all the results show that there was a positive impact of the subsidy on firm growth, either measured by output or inputs, but only for the small firms. This naturally raises the question what the large firms do with the subsidy. In online appendix $\mathrm{H}$, we show tentative evidence that subsidized large firms witness an increase in profits in the same order of magnitude as the subsidy. Apparently, large firms did not react to the subsidy in terms of investment, employment or sales, but simply used the subsidies to increase their profit.

\footnotetext{
${ }^{34} \mathrm{We}$ checked as well whether there is an impact on the exit probability of firms, but failed to find a significant effect.

${ }^{35}$ We checked whether the results changed when including other covariates such as initial value added or initial sales, but found this not to be the case. We have also performed regressions comparing the change in the average value of the indicator before and after the subsidy instead of 4-year cumulative growth and found similar results.
} 
Table 9: Effect of the subsidy on cumulative four year sales growth - interaction with initial log employment

\begin{tabular}{|c|c|c|c|c|c|}
\hline & (1) & $(2)$ & $(3)$ & $(4)$ & (5) \\
\hline & All firms & All firms & All firms & Close firms & Close firms \\
\hline \multicolumn{6}{|l|}{ Sales } \\
\hline \multirow[t]{2}{*}{$D^{s u b s}$} & $0.293^{* *}$ & $0.181^{* *}$ & $0.144^{*}$ & $0.257^{* *}$ & $0.240^{*}$ \\
\hline & $(0.0460)$ & $(0.0592)$ & $(0.0679)$ & $(0.0789)$ & $(0.0953)$ \\
\hline \multirow{2}{*}{$\log (\mathrm{FTE})$ before $\times D^{\text {subs }}$} & $-0.0562^{* *}$ & $-0.0476^{* *}$ & $-0.0410^{*}$ & $-0.0698^{* *}$ & $-0.0650^{*}$ \\
\hline & $(0.0160)$ & $(0.0164)$ & $(0.0168)$ & $(0.0268)$ & $(0.0272)$ \\
\hline \multirow[t]{2}{*}{$\log (\mathrm{FTE})$ before } & $-0.0578^{* *}$ & $-0.0622^{* *}$ & $-0.0622^{* *}$ & $-0.0485^{* *}$ & $-0.0510^{* *}$ \\
\hline & $(0.00701)$ & $(0.00716)$ & $(0.00716)$ & $(0.0163)$ & $(0.0165)$ \\
\hline Observations & 4529 & 4529 & 4529 & 1077 & 1077 \\
\hline$R^{2}$ & 0.078 & 0.093 & 0.097 & 0.101 & 0.131 \\
\hline \multicolumn{6}{|l|}{ Value Added } \\
\hline \multirow[t]{2}{*}{$D^{\text {subs }}$} & $0.419^{* *}$ & $0.258^{* *}$ & $0.257^{* *}$ & $0.257^{*}$ & $0.281^{*}$ \\
\hline & $(0.0588)$ & $(0.0733)$ & $(0.0817)$ & $(0.102)$ & $(0.120)$ \\
\hline \multirow[t]{2}{*}{$\log (\mathrm{FTE})$ before $\times D^{\text {subs }}$} & $-0.0880^{* *}$ & $-0.0745^{* *}$ & $-0.0711^{* *}$ & $-0.0734^{*}$ & $-0.0725^{*}$ \\
\hline & $(0.0196)$ & $(0.0199)$ & $(0.0202)$ & $(0.0337)$ & $(0.0337)$ \\
\hline \multirow[t]{2}{*}{$\log (\mathrm{FTE})$ before } & $-0.125^{* *}$ & $-0.131^{* *}$ & $-0.131^{* *}$ & $-0.121^{* *}$ & $-0.122^{* *}$ \\
\hline & $(0.00855)$ & $(0.00870)$ & $(0.00869)$ & $(0.0206)$ & $(0.0207)$ \\
\hline Observations & 4828 & 4828 & 4828 & 1107 & 1107 \\
\hline$R^{2}$ & 0.109 & 0.126 & 0.129 & 0.143 & 0.175 \\
\hline \multicolumn{6}{|l|}{ Employment } \\
\hline \multirow[t]{2}{*}{$D^{\text {subs }}$} & $0.413^{* *}$ & $0.178^{*}$ & $0.168^{*}$ & $0.239^{*}$ & 0.103 \\
\hline & $(0.0591)$ & $(0.0741)$ & $(0.0822)$ & $(0.106)$ & $(0.125)$ \\
\hline \multirow[t]{2}{*}{$\log (\mathrm{FTE})$ before $\times D^{s u b s}$} & $-0.0744^{* *}$ & $-0.0594^{* *}$ & $-0.0583^{* *}$ & -0.0560 & -0.0429 \\
\hline & $(0.0196)$ & $(0.0200)$ & $(0.0202)$ & $(0.0346)$ & $(0.0350)$ \\
\hline \multirow[t]{2}{*}{$\log (\mathrm{FTE})$ before } & $-0.191^{* *}$ & $-0.198^{* *}$ & $-0.198^{* *}$ & $-0.186^{* *}$ & $-0.193^{* *}$ \\
\hline & $(0.00876)$ & $(0.00885)$ & $(0.00886)$ & $(0.0201)$ & $(0.0204)$ \\
\hline Observations & 4857 & 4857 & 4857 & 1112 & 1112 \\
\hline$R^{2}$ & 0.189 & 0.210 & 0.217 & 0.213 & 0.256 \\
\hline \multirow[t]{2}{*}{ Polynomial Control } & No & $3^{r d}$ Ord. & $2^{n d}$ Ord & No & $1^{s t}$ Ord \\
\hline & & & 2 sides & & 2 sides \\
\hline
\end{tabular}

${ }^{a}$ Robust standard errors in parentheses. ${ }^{+} p<0.10,{ }^{*} p<0.05,{ }^{* *} p<0.01$

${ }^{b}$ Dependent variable: growth in indicator 3 years after the subsidy allocation relative to the year before the subsidy (year '-1')

${ }^{c}$ The columns refer to the 5 different specifications explained in the methodology section. In columns 4 and 5 , the sample is limited to firms close to the cut off, i.e. within $1 / 3$ standard deviation of the score variable. All specifications include call and sector dummies. 


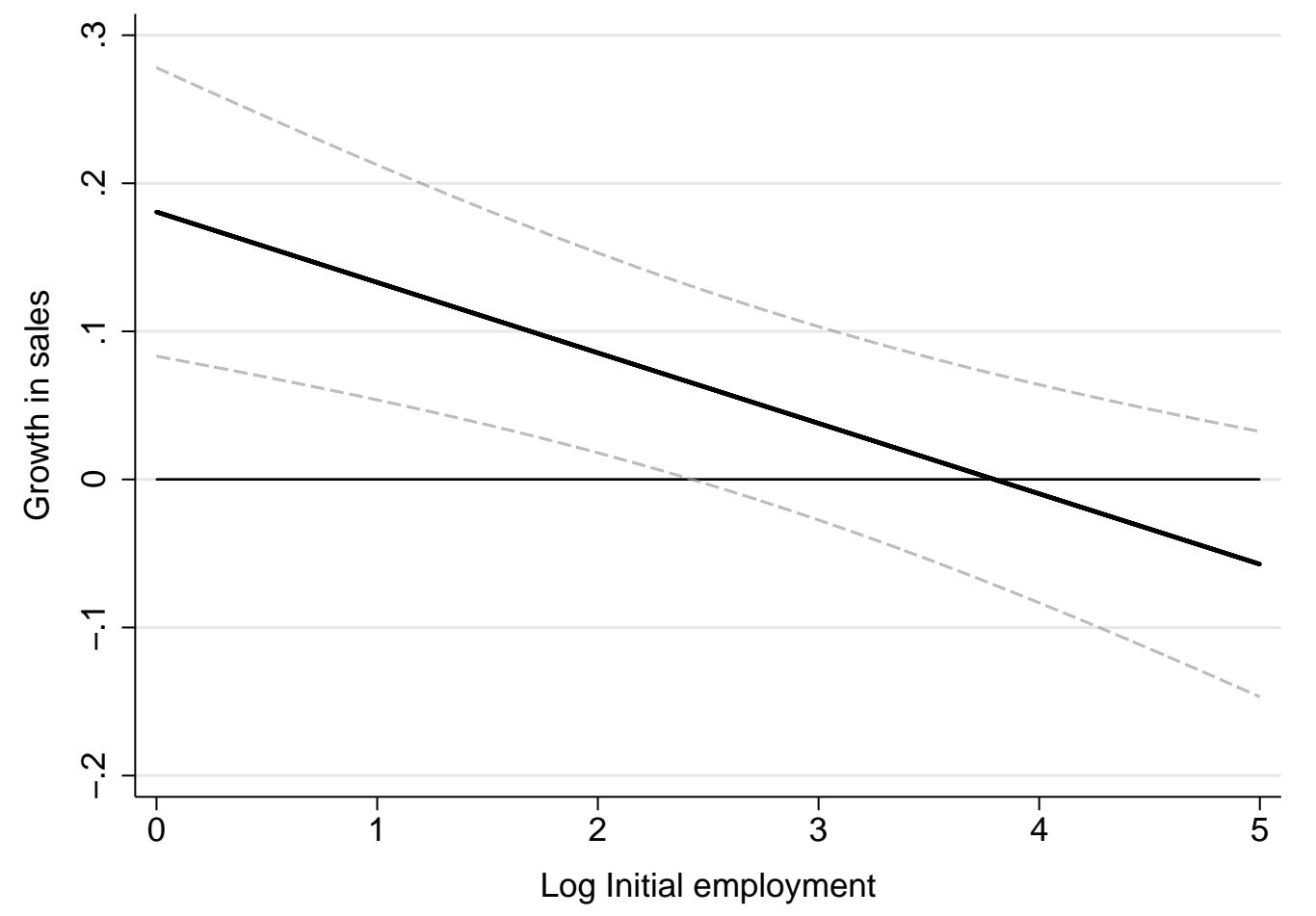

Figure 6: Illustration of the heterogeneous effect on sales growth with regards to initial firm size.

Footnote: Firm size is captured by initial employment in logs. The black line represents the estimated effect according to column 2 of Table 9 , the gray dashed lines indicate the $90 \%$ confidence interval.The variance of the effect is calculated according to the following formula: $\operatorname{var}\left(\frac{\partial \Delta_{4} Y_{i}}{\partial D_{i}^{s u b s}}\right)=$ $\operatorname{var}(\sigma)+\log F T E_{i,-1}^{2} \operatorname{var}(\beta)+2 \log F T E_{i,-1} \operatorname{cov}(\sigma, \beta)$. The point estimate for the effect of the subsidy becomes negative at $3.80 \mathrm{log}$ initial employment, which corresponds to 45 employees.

\subsection{Robustness Checks}

We perform a number of robustness checks. Firstly, we estimate the impact of the subsidy using local linear regression, secondly we estimate the effect for each call separately and lastly we control for differences in the amount of the subsidy received.

\subsubsection{Local Linear Regression}

As a first robustness check, we apply a local linear regression to estimate the effect of the subsidy on our main variables of interest (see Hahn et al., 2001). Our empirical strategy above reflects the rationale behind local linear regression by restricting the sample to 
firms closer and closer to the cut off, so estimating for smaller and smaller bandwidths. The main difference in this subsection is that we now use a triangle kernel and determine the optimal bandwidth following Imbens and Kalyanaraman (2011) ${ }^{36}$ The results are reported in Table 10. We report results for different values of the bandwidth, namely of $75 \%, 100 \%$ and $150 \%$ of the optimal bandwidth. To allow for heterogeneity in the effect for different sizes of the firms, we report as well results for the subsample of small firms, i.e. firms with 10 or less employees before receiving the subsidy. The results are consistent with the main findings of the previous section. While we do not find an effect for the full sample, we find a positive and significant effect of the subsidy for each indicator in the subsample of small firms, although for employment the effect is only significant at the $10 \%$ level.

\subsubsection{Estimation per Call}

As a second robustness check we estimate the effect of the subsidy for each call separately instead of pooling the observations and running the regressions with call dummies and call specific controls for the score. We subsequently compute the aggregate effects by taking a weighted average of the call specific estimates. We use two different weighting schemes, following Cerqua and Pellegrini (2014). First, we give more weight to the estimates with smaller variances, so the aggregate effect and its standard error are:

$$
\begin{aligned}
\beta^{a g g r} & =\left(\sum_{c} \beta_{c} / \sigma_{c}^{2}\right) /\left(\sum_{c} 1 / \sigma_{c}^{2}\right) \\
\sigma^{a g g r} & =\sqrt{1 /\left(\sum_{c} 1 / \sigma_{c}^{2}\right)}
\end{aligned}
$$

with $\beta_{c}$ the coefficient estimate of call $c$ and $\sigma_{c}$ its standard error.

Second, we use the number of observations used in the estimation as weights:

$$
\begin{aligned}
\beta^{a g g r} & =\sum_{c} N_{c} \beta_{c} / N \\
\sigma^{a g g r} & =\sqrt{\sum_{c} N_{c}^{2} \sigma_{c}^{2} / N^{2}}
\end{aligned}
$$

\footnotetext{
${ }^{36}$ We first standardize the score before including it in the local linear regression. We used the rd module in stata to execute this analysis. (Nichols, 2011)
} 
Table 10: Local linear regression with triangle kernel

\begin{tabular}{lcccc}
\hline \hline & Fixed Assets & Employment & Sales & Value Added \\
\hline All Firms & & & & \\
Bandwidth 100\% & 0.1462 & 0.0512 & 0.0858 & 0.0801 \\
& $(0.212)$ & $(0.0612)$ & $(0.0537)$ & $(0.0604)$ \\
Bandwidth 75\% & 0.1564 & 0.0579 & $0.1057^{+}$ & 0.1015 \\
& $(0.2423)$ & $(0.0682)$ & $(0.0604)$ & $(0.0676)$ \\
Bandwidth 150\% & 0.1789 & 0.0318 & 0.0534 & 0.0606 \\
& $(0.1808)$ & $(0.0517)$ & $(0.0458)$ & $(0.0513)$ \\
Bandwidth & 1.091 & 0.8253 & 0.6866 & 0.924 \\
& & & & \\
Small Firms & & & & \\
Bandwidth 100\% & $0.5894^{+}$ & $0.1643^{+}$ & $0.1389^{*}$ & $0.2093^{*}$ \\
Bandwidth 75\% & $(0.3536)$ & $(0.0983)$ & $(0.0700)$ & $(0.0974)$ \\
& 0.5893 & $0.1921^{+}$ & $0.1568^{*}$ & $0.2336^{*}$ \\
Bandwidth 150\% & $(0.4048)$ & $(0.113)$ & $(0.0789)$ & $(0.1104)$ \\
Bandwidth & $0.6208^{*}$ & $0.1542^{+}$ & $0.1424^{*}$ & $0.1707^{*}$ \\
\hline \hline
\end{tabular}

${ }^{a}$ Standard errors in parentheses. ${ }^{+} p<0.10,{ }^{*} p<0.05,{ }^{* *} p<0.01$

${ }^{b}$ Dependent variable: growth in employment 3 years after the subsidy allocation relative to the year before the subsidy (year '-1')

${ }^{c}$ Local linear regression using a triangle kernel

The results where we use the inverse of the variance as weights are presented in Table 11. Online appendix F reports the findings for applying the number of observations. The findings are in line with the previously reported results, namely a positive effect of the subsidy on firm growth, but only for the small firms. 
Table 11: Estimations for each call separately

\begin{tabular}{|c|c|c|c|c|c|}
\hline & $\begin{array}{c}(1) \\
\text { All Firms }\end{array}$ & $\begin{array}{c}(2) \\
\text { All Firms }\end{array}$ & $\begin{array}{c}(3) \\
\text { All Firms }\end{array}$ & $\begin{array}{c}(4) \\
\text { Close Firms }\end{array}$ & $\begin{array}{c}(5) \\
\text { Close Firms }\end{array}$ \\
\hline \multicolumn{6}{|l|}{ Fixed Assets } \\
\hline$D^{s u b s}$ & $\begin{array}{l}0.6001^{* *} \\
(0.2233)\end{array}$ & $\begin{array}{l}0.5011^{+} \\
(0.2764)\end{array}$ & $\begin{array}{c}0.3158 \\
(0.2809)\end{array}$ & $\begin{array}{c}0.5897^{*} \\
(0.2654)\end{array}$ & $\begin{array}{c}0.3752 \\
(0.3796)\end{array}$ \\
\hline $\log (\mathrm{FTE})$ before $\times D^{\text {subs }}$ & $\begin{array}{l}-0.1099 \\
(0.0721)\end{array}$ & $\begin{array}{l}-0.1065 \\
(0.0723)\end{array}$ & $\begin{array}{c}-0.0798 \\
(0.0719)\end{array}$ & $\begin{array}{c}-0.0362 \\
(0.0849)\end{array}$ & $\begin{array}{l}-0.0103 \\
(0.0893)\end{array}$ \\
\hline $\log$ (FTE) before & $\begin{array}{c}-0.3409^{* *} \\
(0.035)\end{array}$ & $\begin{array}{c}-0.3407^{* *} \\
(0.0355)\end{array}$ & $\begin{array}{l}-0.336^{* *} \\
(0.0355)\end{array}$ & $\begin{array}{l}-0.0849 \\
(0.0521)\end{array}$ & $\begin{array}{l}-0.0325 \\
(0.0384)\end{array}$ \\
\hline \multicolumn{6}{|l|}{ Sales } \\
\hline$D^{\text {subs }}$ & $\begin{array}{l}0.2769^{* *} \\
(0.0454)\end{array}$ & $\begin{array}{c}0.1874^{* *} \\
(0.0583)\end{array}$ & $\begin{array}{c}0.1394^{*} \\
(0.0622)\end{array}$ & $\begin{array}{l}0.2623^{* *} \\
(0.0777)\end{array}$ & $\begin{array}{c}0.187^{+} \\
(0.0994)\end{array}$ \\
\hline $\log (\mathrm{FTE})$ before $\times D^{\text {subs }}$ & $\begin{array}{c}-0.0473^{* *} \\
(0.016)\end{array}$ & $\begin{array}{l}-0.0362^{*} \\
(0.0162)\end{array}$ & $\begin{array}{c}-0.0315^{+} \\
(0.0165)\end{array}$ & $\begin{array}{l}-0.0429 \\
(0.0273)\end{array}$ & $\begin{array}{c}-0.0508^{+} \\
(0.0281)\end{array}$ \\
\hline $\log$ (FTE) before & $\begin{array}{c}-0.0607^{* *} \\
(0.0071)\end{array}$ & $\begin{array}{c}-0.0664^{* *} \\
(0.0072)\end{array}$ & $\begin{array}{c}-0.0669^{* *} \\
(0.0072)\end{array}$ & $\begin{array}{c}-0.0370^{*} \\
(0.0162)\end{array}$ & $\begin{array}{c}-0.0319^{*} \\
(0.0159)\end{array}$ \\
\hline $\begin{array}{l}\text { Value Added } \\
D_{\text {subs }}\end{array}$ & & & & & \\
\hline$D^{\text {subs }}$ & $\begin{array}{l}0.4132^{* *} \\
(0.0589)\end{array}$ & $\begin{array}{l}0.2571^{* *} \\
(0.0731)\end{array}$ & $\begin{array}{l}0.2163^{* *} \\
(0.0756)\end{array}$ & $\begin{array}{l}0.1346 \\
(0.099)\end{array}$ & $\begin{array}{c}0.1218 \\
(0.1236)\end{array}$ \\
\hline $\log (\mathrm{FTE})$ before $\times D^{\text {subs }}$ & $\begin{array}{c}-0.0862^{* *} \\
(0.0198)\end{array}$ & $\begin{array}{c}-0.0721^{* *} \\
(0.0201)\end{array}$ & $\begin{array}{c}-0.0638^{* *} \\
(0.0201)\end{array}$ & $\begin{array}{c}-0.024 \\
(0.0341)\end{array}$ & $\begin{array}{l}-0.0314 \\
(0.0349)\end{array}$ \\
\hline $\log$ (FTE) before & $\begin{array}{c}-0.1259^{* *} \\
(0.0085)\end{array}$ & $\begin{array}{c}-0.1316^{* *} \\
(0.0087)\end{array}$ & $\begin{array}{c}-0.1318^{* *} \\
(0.0087)\end{array}$ & $\begin{array}{c}-0.1063^{* *} \\
(0.0199)\end{array}$ & $\begin{array}{c}-0.1065^{* *} \\
(0.0203)\end{array}$ \\
\hline Employment & & & & & \\
\hline$D^{\text {subs }}$ & $\begin{array}{l}0.4223^{* *} \\
(0.0574)\end{array}$ & $\begin{array}{l}0.2234^{* *} \\
(0.0711)\end{array}$ & $\begin{array}{c}0.2128^{* *} \\
(0.073)\end{array}$ & $\begin{array}{c}0.2979^{* *} \\
(0.099)\end{array}$ & $\begin{array}{c}0.0883 \\
(0.1172)\end{array}$ \\
\hline $\log (\mathrm{FTE})$ before $\times D^{\text {subs }}$ & $\begin{array}{c}-0.0777^{* *} \\
(0.0191)\end{array}$ & $\begin{array}{c}-0.0599^{* *} \\
(0.0193)\end{array}$ & $\begin{array}{c}-0.0545^{* *} \\
(0.0191)\end{array}$ & $\begin{array}{c}-0.0556^{+} \\
(0.0337)\end{array}$ & $\begin{array}{l}-0.0504 \\
(0.0338)\end{array}$ \\
\hline $\log$ (FTE) before & $\begin{array}{l}-0.193^{* *} \\
(0.0089)\end{array}$ & $\begin{array}{c}-0.2013^{* *} \\
(0.0089)\end{array}$ & $\begin{array}{c}-0.2021^{* *} \\
(0.0089)\end{array}$ & $\begin{array}{c}-0.1648^{* *} \\
(0.0187)\end{array}$ & $\begin{array}{c}-0.1663^{* *} \\
(0.0190)\end{array}$ \\
\hline
\end{tabular}

${ }^{a}$ Robust standard errors in parentheses. ${ }^{+} p<0.10,{ }^{*} p<0.05,{ }^{* *} p<0.01$

${ }^{b}$ Dependent variable: growth in indicator 3 years after the subsidy allocation relative to the year before the subsidy (year '-1')

${ }^{c}$ The columns refer to the 5 different specifications explained in the methodology section. In columns 4 and 5 , the sample is limited to firms close to the cut off, i.e. within $1 / 3$ standard deviation of the score variable.

${ }^{d}$ Equations estimated per call and estimates aggregated up using the inverse of the variance as weights. 


\subsubsection{Subsidy Amount Relative to Size}

A possible explanation for the heterogeneity in size is that smaller firms simply receive a higher subsidy relative to their size. If the same amount of subsidy is given to a small and a large firm, the former is likely to experience a higher boost thanks to the subsidy. In our data, we see that smaller firms indeed received a higher subsidy relative to their size: if we regress the log of the subsidy amount on the log initial employment of the firms that received the subsidy, we find that a $10 \%$ increase in employment implies only a 3 to $4 \%$ increase in the subsidy amount. To check if this explains our results, we used a continuous measure of subsidy relative to firm size rather than the simple dummy $D^{s u b s}$. More specifically, we used the subsidy amount relative to the initial employment of the firm in the year before the subsidy was awarded. We check whether the impact of the subsidy amount per employee is lower for large firms compared to small firms by including the interaction between initial employment and the relative subsidy amount. If we again find the interaction to be negative, the lower impact of receiving the subsidy for large firms is not entirely due to a lower subsidy amount per employee. There is an additional complication in the empirical specification: the RDD methodology controls for the non-random subsidy decision by the government, but the requested subsidy amount by the firm could still be endogenous, i.e. firms requesting a higher subsidy amount are more likely to invest more. Consequently simply regressing the outcome on the continuous subsidy measure could create an upward bias in the estimate for the impact of the subsidy. However, for our purposes, we are mostly interested in the coefficient on the interaction between initial employment and the received subsidy and endogeneity will only drive this estimate when there is a difference in the endogeneity bias between small and large firms ${ }^{37}$ The results for the cumulative growth in fixed assets are shown in Table 12 and for sales in Table 13 . In Table 12 we see qualitatively a similar picture as before: the effect is highest for the smallest firms and decreases with firm size. The statistical significance is lower, but this is not surprising ${ }^{38}$ We added an

\footnotetext{
${ }^{37} \mathrm{We}$ also included the amount of requested subsidies next to the received subsidies in the regression equation. The idea is that the requested subsidies could control for the endogeneity issue by picking up the relation between the requested subsidies and the planned size of the investment, thereby affecting firm growth. The results of including this extra control are highly similar to the one reported in the paper.

${ }^{38}$ The statistical significance will likely drop due to two reasons. First, estimating a continuous effect is more data-demanding than estimating the coefficient of the simple dummy $D^{\text {subs }}$ in the baseline specification. Second, the applications for firms that receive the subsidy multiple times are not taken into account, possibly underestimating the subsidy amount received and thus introducing measurement error.
} 
additional symbol \# in the table to indicate that the coefficients are significant at the 20\% significance level. The results in Table 13 for sales are in line with these results, but the coefficients here are statistically significant at the traditional significance levels. Moreover, the results are consistent with the previous results in terms of magnitude. The results for value added and employment are in line with the results for sales and are omitted to save space. All in all, the results indicate that the different impact of the subsidy according to firm size is not (entirely) due to differences in the relative subsidy amount. This is consistent with for example the findings of Bronzini and Iachini (2014) who provide evidence for the greater effect of R\&D subsidies on small firms being due to financial frictions.

Table 12: Effect of the subsidy intensity on cumulative four year fixed assets growth after receiving the subsidy - interaction with initial log employment

\begin{tabular}{|c|c|c|c|c|c|}
\hline & (1) & $(2)$ & (3) & (4) & (5) \\
\hline & All firms & All firms & All firms & Close firms & Close firms \\
\hline \multirow[t]{2}{*}{$\log (s u b s / F T E)$} & $0.0856^{* *}$ & $0.101^{* *}$ & $0.126^{* *}$ & $0.0797^{+}$ & $0.109^{*}$ \\
\hline & $(0.0245)$ & $(0.0296)$ & $(0.0322)$ & $(0.0420)$ & $(0.0483)$ \\
\hline \multirow[t]{2}{*}{$\log (F T E) b e f . \times \log ($ subs $/ F T E)$} & $-0.0139^{\#}$ & -0.0103 & -0.00765 & $-0.0220^{\#}$ & $-0.0213^{\#}$ \\
\hline & $(0.00876)$ & $(0.00886)$ & $(0.00891)$ & $(0.0146)$ & $(0.0143)$ \\
\hline \multirow[t]{2}{*}{$\log (F T E)$ before } & $-0.341^{* *}$ & $-0.341^{* *}$ & $-0.340^{* *}$ & $-0.308^{* *}$ & $-0.290^{* *}$ \\
\hline & $(0.0349)$ & $(0.0356)$ & $(0.0356)$ & $(0.0772)$ & $(0.0771)$ \\
\hline Observations & 4857 & 4857 & 4857 & 1112 & 1112 \\
\hline$R^{2}$ & 0.063 & 0.075 & 0.080 & 0.114 & 0.162 \\
\hline \multicolumn{6}{|c|}{$\begin{array}{l}\text { Robust standard errors in parentheses. }{ }^{\#} p<0.20,{ }^{+} p<0.10,{ }^{*} p<0.05,{ }^{* *} p<0.01 \\
\text { Dependent variable: cumulative growth in fixed assets } 3 \text { years after the subsidy allocation relative to th } \\
\text { year before the subsidy (year '-1') } \\
\text { The columns refer to the } 5 \text { different specifications explained in the methodology section. In columns } 4 \\
\text { and } 5 \text {, the sample is limited to firms close to the cut off, i.e. within } 1 / 3 \text { standard deviation of the scor }\end{array}$} \\
\hline
\end{tabular}


Table 13: Effect of the subsidy intensity on cumulative four year sales growth after receiving the subsidy - interaction with initial log employment

\begin{tabular}{lccccc}
\hline \hline & $(1)$ & $(2)$ & $(3)$ & $(4)$ & $(5)$ \\
& All firms & All firms & All firms & Close firms & Close firms \\
\hline $\log ($ subs $/ F T E)$ & $0.0302^{* *}$ & $0.0206^{* *}$ & $0.0180^{* *}$ & $0.0281^{* *}$ & $0.0299^{* *}$ \\
& $(0.00489)$ & $(0.00608)$ & $(0.00683)$ & $(0.00849)$ & $(0.00987)$ \\
$\log ($ FTE $)$ bef. $\times \log ($ subs $/ F T E)$ & $-0.00477^{*}$ & $-0.00453^{*}$ & $-0.00393^{*}$ & $-0.00704^{*}$ & $-0.00666^{*}$ \\
& $(0.00187)$ & $(0.00191)$ & $(0.00195)$ & $(0.00308)$ & $(0.00310)$ \\
$\log ($ FTE $)$ before & & & & & \\
& $-0.0581^{* *}$ & $-0.0626^{* *}$ & $-0.0626^{* *}$ & $-0.0491^{* *}$ & $-0.0502^{* *}$ \\
\hline Observations & $(0.00699)$ & $(0.00714)$ & $(0.00714)$ & $(0.0162)$ & $(0.0164)$ \\
$R^{2}$ & 4529 & 4529 & 4529 & 1077 & 1077 \\
\hline \hline
\end{tabular}

${ }^{a} \overline{\text { Robust standard errors in parentheses. }{ }^{\#} p<0.20,{ }^{+} p<0.10,{ }^{*} p<0.05,{ }^{* *} p<0.01}$

${ }^{b}$ Dependent variable: cumulative growth in fixed assets 3 years after the subsidy allocation relative to the year before the subsidy (year '-1')

${ }^{c}$ The columns refer to the 5 different specifications explained in the methodology section. In columns 4 and 5 , the sample is limited to firms close to the cut off, i.e. within $1 / 3$ standard deviation of the score variable. All specifications include call and sector dummies.

\section{Additional Results}

The current section presents some additional results, namely we first measure the impact of the subsidy on productivity and second, we assess the cost effectiveness of the subsidy by calculating the cost per job created.

\subsection{Impact on productivity}

This subsection shows the results for productivity. The analysis is complicated by the fact that the very small firms (micro-firms), namely firms with only 1 or 2 employees, are exceptionally productive. ${ }^{39}$ The main explanation we see is that the owner of the firm is not always reported as an employee of the firm, even if active in the firm 40

\footnotetext{
${ }^{39}$ For example, in terms of labor productivity, firms with one employee are approximately $60 \%$ more productive than firms with more than 3 employees. For firms with 2 and 3 employees these premia are respectively approximately $28 \%$ and $13 \%$.

${ }^{40}$ The owner is at least partly paid through the profits of the firm. Some owners choose to be an employee of their firm, e.g. for tax reasons (if they pay themselves a low wage, the tax rate on their wage is lower than the corporate taxes), but not all owners do this. We see for instance many firms reporting zero employment in their accounting statements.
} 
This creates a positive measurement bias of labor productivity for small firms, which is more severe the lower the number of FTE's. An alternative explanation is that the marginal product of the employees diminishes with each extra employee that the firm hires. Irrespective of the reason way micro-firms are more productive and increasingly so the smaller they are, this is potentially problematic in the context of this paper as we found evidence that the subsidy increased employment for the very small firms. Hence, we need to control for this in our analysis.

We mitigate this problem in two ways: in our main specification, we use detailed controls for firm employment 41 As a robustness check, we run the analysis again with labor productivity calculated as value added per 'FTE plus 1'. The results are qualitatively the same ${ }^{42}$

The results for the cumulative growth, i.e. the growth in labor productivity 3 years after the subsidy allocation relative to the year before the subsidy (year '-1'), are shown in the upper pane of Table 14. The first column again shows that a simple comparison shows that firms that received the subsidy experienced a higher growth in labor productivity. When estimating the effect in the next 4 columns, we find a positive effect for the smallest firms that decreases with increasing firm size.

Next, we estimate the effect on TFP by running similar regressions, still with labor productivity as a dependent variable, but controlling for fixed assets, which controls for the fact that labor productivity could be systematically higher for firms that use more capital. The results are shown in Table 14. We see qualitatively the same results as before, although the significance level drops somewhat. We can conclude that the subsidy had an impact on productivity of small firms, both on labor productivity and TFP.

\footnotetext{
${ }^{41}$ More specifically, we add separate dummies for a FTE of respectively one, two and three. We also add $\log$ FTE as a general control for the number of FTE's. The details on the exact implementation are explained in online appendix G.

${ }^{42}$ The results for this robustness check are available on request.
} 
Table 14: Effect of the subsidy on cumulative labor productivity growth - interaction with initial log employment

\begin{tabular}{|c|c|c|c|c|c|}
\hline & (1) & $(2)$ & $(3)$ & (4) & (5) \\
\hline & All firms & All firms & All firms & Close firms & Close firms \\
\hline \multicolumn{6}{|l|}{ Labor Productivity } \\
\hline \multirow[t]{2}{*}{$D^{s u b s}$} & $0.137^{* *}$ & $0.128^{* *}$ & $0.103^{*}$ & 0.0850 & $0.136^{*}$ \\
\hline & $(0.0324)$ & $(0.0397)$ & $(0.0456)$ & $(0.0523)$ & $(0.0638)$ \\
\hline \multirow[t]{2}{*}{$\log (\mathrm{FTE})$ before $\times D^{\text {subs }}$} & $-0.0411^{* *}$ & $-0.0373^{* *}$ & $-0.0330^{* *}$ & $-0.0344^{*}$ & $-0.0381^{*}$ \\
\hline & $(0.0106)$ & $(0.0107)$ & $(0.0110)$ & $(0.0175)$ & $(0.0176)$ \\
\hline Observations & 4828 & 4828 & 4828 & 1107 & 1107 \\
\hline$R^{2}$ & 0.148 & 0.160 & 0.164 & 0.141 & 0.162 \\
\hline
\end{tabular}

\section{Total Factor Productivity}

\begin{tabular}{lccccc}
$D^{\text {subs }}$ & $0.117^{* *}$ & $0.110^{* *}$ & $0.0827^{+}$ & 0.0726 & $0.121^{+}$ \\
& $(0.0312)$ & $(0.0383)$ & $(0.0440)$ & $(0.0519)$ & $(0.0631)$ \\
$\log (\mathrm{FTE})$ before $\times D^{\text {subs }}$ & $-0.0361^{* *}$ & $-0.0329^{* *}$ & $-0.0289^{* *}$ & $-0.0299^{+}$ & $-0.0328^{+}$ \\
& $(0.0102)$ & $(0.0104)$ & $(0.0106)$ & $(0.0173)$ & $(0.0174)$ \\
\hline Observations & 4828 & 4828 & 4828 & 1107 & 1107 \\
$R^{2}$ & 0.187 & 0.197 & 0.200 & 0.168 & 0.187 \\
\hline \multirow{2}{*}{ Polynomial Control } & No & $3^{\text {rd } \text { Ord. }}$ & $2^{\text {nd } \text { Ord. }}$ & No & $1^{\text {st } \text { Ord. }}$ \\
& & & 2 sides & & 2 sides
\end{tabular}

$\overline{\bar{a}}$ Robust standard errors in parentheses. ${ }^{+} p<0.10,{ }^{*} p<0.05,{ }^{* *} p<0.01$

${ }^{b}$ Dependent variable: growth in labor productivity 3 years after the subsidy allocation relative to the year before the subsidy (year '-1'). Labor productivity is defined as value added per FTE.

${ }^{c}$ The columns refer to the 5 different specifications explained in the methodology section. In columns 4 and 5 , the sample is limited to firms close to the cut off, i.e. within $1 / 3$ standard deviation of the score variable. All specifications include call and sector dummies.

${ }^{d}$ The regressions also control for different productivity growth according to firm size, see appendix G for a detailed description.

${ }^{e}$ The coefficients in the bottom pane can be interpreted as the effect on TFP because we control for growth in fixed assets, see online appendix $\mathrm{G}$ for a detailed description. 


\subsection{Subsidy per created job}

The previous paragraphs show that we only find an effect on growth for the smallest firms. However, from these results it is still difficult to judge how cost-efficient the program was. To get a sense of the cost-efficiency and to be able to compare with other studies, we calculate the subsidy amount per created job in the subsidized firms. To this end, we take the RDD specifications in the last four columns of table 9, and calculate the estimated growth in employment in the neighborhood of the cut off (i.e., we limit the sample to firms within $1 / 3$ standard deviation of the score variable). E.g. according to column 2 in table 9, firms with one FTE experience a growth of about $18 \%$ in employment. So the estimated job growth for these firms is 0.18 jobs. For firms with ten FTE's, the estimated job growth is 0.41 jobs ${ }^{43}$ For firms that experience a negative employment growth due to the fitted model, we set the employment growth to zero ${ }_{44}^{4}$

We aggregate these estimates in firm-level job growth to get the total job growth in the neighbourhood of the cut off. Next, we also aggregate the subsidy amounts corresponding to these firms. Of the 1112 firms we observe near the cut off (i.e. the number of observations in columns 4 and 5), 410 firms get the subsidy. According to the specification in column 2 , the aggregate job growth due to the subsidy was about 78 jobs for these firms. The total amount of subsidy spent on these 410 firms is $€ 35 \mathrm{M}$. The estimated subsidy spent per created job in the subsidized firms is therefore about $€ 450 \mathrm{~K}$ according to this specification. If we take the average across the four RDD specifications, column 2 to 5 in table 9, we find a number of $€ 488 \mathrm{~K}$, or almost $€ 500 \mathrm{~K}$. The high cost is not solely driven by the fact that there is no employment effect for the larger firms. Even if we limit the calculation to firms with ten FTE's or less, the estimated cost per job is $€ 189 \mathrm{~K}$, which is still high compared to the estimates in the other papers.

Note that this measure does not take negative or positive spillovers to other firms into account, neither the administrative cost for the government and the firms that applied. Nonetheless, this number suggests that the program was an expensive way to create jobs. Theoretically, this can be explained by firms substituting capital for labor due to the lower costs of capital. The total effect on labor would then be a combination of this negative substitution effect and a positive scale effect, i.e. firms generating

\footnotetext{
${ }^{43}$ Calculated as $(0.178-0.0594 \cdot \log (10)) \cdot 10$.

${ }^{44}$ Theoretically it is possible that a capital subsidy has a negative impact on employment growth. However, given the previous results, it seems more likely that the larger firms simply did not invest more due to the subsidy, and hence the effect on employment was also zero.
} 
more output. Other subsidy systems try to mitigate the substitution effect by adding a criterion that the project should lead to the creation of new jobs and found substantially lower costs 45 Note however that these are not the only differences with those subsidy schemes, so it remains to be seen how much of the cost difference can be attributed to this condition.

\section{Conclusion}

This paper determines the effect of investment subsidies granted in Flanders between 2004 and 2009. The goal of these subsidies was to financially support well performing companies in their investment decisions, thereby stimulating growth and competitiveness. We evaluate the impact of these subsidies on the outcomes for the firms receiving the subsidy: growth in fixed assets, output, employment and productivity. Our paper is one of the only papers to exploit a quasi-experimental setting in evaluating the effectiveness of subsidies. The ranking system of the applications creates a sharp cut off, allowing us to credibly estimate a causal effect around the subsidy cut off using RDD.

We find that the effect of the subsidies on the growth of the receiving firms was rather limited. Only for the very small firms, we find a positive effect on investment, employment, sales, value added and productivity. For larger firms, we do not find any effect. The heterogeneous effect in terms of size confirms earlier results of Bronzini and Iachini (2014), Cerqua and Pellegrini (2014) and Criscuolo et al. (2012). Our evidence suggests that larger firms use the subsidy to finance investments they would have undertaken anyway.

The positive effect on growth is moreover limited, relative to the cost of the subsidy. For example, we estimate the subsidy spending per created job to be $€ 500 \mathrm{~K}$. Given the setup of the subsidy, this is not that surprising. First, the subsidy is aimed at firms that have been well performing in the past and favors investments financed with a high fraction of the firm's own funds. Consequently, these firms are less likely to be credit constrained and the subsidy is more likely to finance investment projects that would have been executed as well in its absence. Second, the subsidy as a percentage of the total investment was relatively low, having a more limited impact on the profitability

\footnotetext{
${ }^{45}$ Cerqua and Pellegrini (2014) estimate the same measure for Law 488 in Italy to be about $€ 62 \mathrm{~K} /$ job. Criscuolo et al. (2012) estimate a different measure for the RSA program in the UK, i.e. total jobs created (using estimates at the area level rather than the firm level) over the total cost of the program (including administrative costs and taxation). Their estimate is about $€ 6 \mathrm{~K} / \mathrm{job}$.
} 
of the investment project. To avoid that the subsidy are mainly windfall gains to the receiving firms, we would recommend to exclude certain criteria, especially the ones for autofinancing and cash flow, as these go against one of the main rationales to grant investment subsidies, namely enterprises being unable to execute a profitable investment project because of credit constraints. Potentially, other criteria could be added such as the new job creation and whether the investment would have occurred in the absence of the government support. These led to for example in the UK and Italy to a substantially higher cost effectiveness of investment subsidies (Cerqua and Pellegrini, 2014; Criscuolo et al., 2012) .

In terms of competitiveness, it appears that the productivity of the subsidized firms has increased in comparison to non-subsidized firms, but how this would translate in growth in the long run is still an open research question that we leave for future research. 


\section{References}

Aghion, P., J. Boulanger, and E. Cohen (2011). Rethinking industrial policy. Bruegel Policy Brief 2011/4.

Aghion, P., M. Dewatripont, L. Du, A. Harrison, and P. Legros (2015). Industrial policy and competition. American Economic Journal: Macroeconomics 7(4), 1 - 32 . doi:http://dx.doi .org/10.1257/mac . 20120103.

Angrist, J. D. and J.-S. Pischke (2008). Mostly harmless econometrics: An empiricist's companion. Princeton University Press.

Bergström, F. (2000). Capital subsidies and the performance of firms. Small Business Economics 14(3), 183-193. doi: http://dx.doi.org/10.1023/A:1008133217594.

Bernini, C. and G. Pellegrini (2011). How are growth and productivity in private firms affected by public subsidy? evidence from a regional policy. Regional Science and Urban Economics 41(3), 253-265. doi: http://dx.doi.org/10.1016/j.regsciurbeco. 2011.01 .005 .

Bia, M. and A. Mattei (2012). Assessing the effect of the amount of financial aids to piedmont firms using the generalized propensity score. Statistical Methods \& Applications 21 (4), 485-516. doi: http://dx.doi.org/10.1007/s10260-012-0193-4.

Bondonio, D. and R. T. Greenbaum (2012). Revitalizing regional economies through enterprise support policies: an impact evaluation of multiple instruments. European Urban and Regional Studies. doi: http://dx.doi.org/10.1177/0969776411432986.

Bronzini, R. and G. de Blasio (2006). Evaluating the impact of investment incentives: The case of italy's law 488/1992. Journal of Urban Economics 60(2), 327-349. doi: http://dx.doi.org/10.1016/j.jue.2006.03.005.

Bronzini, R. and E. Iachini (2014). Are incentives for r\&d effective? evidence from a regression discontinuity approach. American Economic Journal: Economic Policy 6(4). doi: http://dx.doi.org/10.1257/pol.6.4.100.

Cerqua, A. and G. Pellegrini (2014). Do subsidies to private capital boost firms' growth? a multiple regression discontinuity design approach. Journal of Public Economics 109, 114-126. doi: http://dx.doi.org/10.1016/j.jpubeco.2013.11.005.

Criscuolo, C., R. Martin, H. Overman, and J. Van Reenen (2012). The causal effects of an industrial policy. Technical report, National Bureau of Economic Research. doi: http://dx.doi.org/10.3386/w17842.

Czarnitzki, D. and C. Lopes-Bento (2013). Value for money? new microeconometric evidence on public r\&d grants in flanders. Research Policy 42(1), 76-89. doi: http://dx.doi.org/10.1016/j.respol.2012.04.008. 
Daly, M., I. Gorman, G. Lenjosek, A. MacNevin, and W. Phiriyapreunt (1993). The impact of regional investment incentives on employment and productivity: Some canadian evidence. Regional Science and Urban Economics 23(4), 559-575. doi: http://dx.doi.org/10.1016/0166-0462(93)90047-i.

Devereux, M. P., R. Griffith, and H. Simpson (2007). Firm location decisions, regional grants and agglomeration externalities. Journal of Public Economics 91(3), 413-435. doi: http://dx.doi.org/10.2139/ssrn.1308573.

González, X., J. Jaumandreu, and C. Pazó (2005). Barriers to innovation and subsidy effectiveness. RAND Journal of Economics, 930-950.

Hahn, J., P. Todd, and W. Van der Klaauw (2001). Identification and estimation of treatment effects with a regression-discontinuity design. Econometrica 69(1), 201-209. doi:http://dx.doi.org/10.1111/1468-0262.00183.

Ham, J. C., C. Swenson, A. İmrohoroğlu, and H. Song (2011). Government programs can improve local labor markets: Evidence from state enterprise zones, federal empowerment zones and federal enterprise community. Journal of Public Economics 95(7), 779-797. doi: http://dx.doi.org/10.1016/j.jpubeco.2010.11.027.

Harris, R. and C. Robinson (2005). Impact of regional selective assistance on sources of productivity growth: Plant-level evidence from uk manufacturing, 1990-98. Regional Studies 39(6), 751-765. doi: http://dx.doi.org/10.1080/00343400500213648.

Harris, R. and M. Trainor (2005). Capital subsidies and their impact on total factor productivity: Firm-level evidence from northern ireland. Journal of Regional Science 45(1), 49-74. doi: http://dx.doi.org/10.1111/j.0022-4146.2005.00364.x.

Imbens, G. and K. Kalyanaraman (2011). Optimal bandwidth choice for the regression discontinuity estimator. The Review of Economic Studies. doi: http://dx.doi.org/ 10.1093/restud/rdr043.

Jacob, B. A. and L. Lefgren (2011). The impact of research grant funding on scientific productivity. Journal of Public Economics 95(9), 1168-1177. doi: http://dx.doi. org/10.1016/j.jpubeco.2011.05.005.

Koski, H. and M. Pajarinen (2013). The role of business subsidies in job creation of start-ups, gazelles and incumbents. Small Business Economics 41(1), 195-214. doi: http://dx.doi.org/10.1007/s11187-012-9420-5.

Lee, D. S. and T. Lemieux (2010). Regression discontinuity designs in economics. Journal of Economic Literature 48, 281-355. doi: http://dx.doi.org/10.1257/jel.48.2. 281. 
McCrary, J. (2008). Manipulation of the running variable in the regression discontinuity design: A density test. Journal of Econometrics 142(2), 698-714. doi: http: //dx.doi.org/10.1016/j.jeconom.2007.05.005.

Nichols, A. (2011). rd 2.0: Revised stata module for regression discontinuity estimation. http://ideas.repec.org/c/boc/bocode/s456888.html.

Ooghe, H. and C. Spaenjers (2005). Groeipremie voor kmo's - evaluatie van de eerste en tweede call. Technical report, Steunpunt voor Ondernemen en Internationaal Ondernemen (STOIO).

Rodrik, D. (2012). Why we learn nothing from regressing economic growth on policies. Seoul Journal of Economics 25(2), 137-151.

Schalk, H. J. and G. Untiedt (2000). Regional investment incentives in germany: Impacts on factor demand and growth. The Annals of Regional Science 34(2), 173-195. doi: http://dx.doi.org/10.1007/s001689900008.

Tokila, A. and M. Haapanen (2012, May). Evaluation of deadweight spending in regional enterprise financing. Regional Studies 46(2), 185-201. doi: http://dx.doi.org/10. 1080/00343404.2010.497134.

Wren, C. (1998). Subsidies for job creation: is small best? Small Business Economics 10(3), 273-281. doi: http://dx.doi.org/10.1023/a:1007994301635. 